Review Article

\title{
A Minireview of the Natures of Radiation-Induced Point Defects in Pure and Doped Silica Glasses and Their Visible/Near-IR Absorption Bands, with Emphasis on Self-Trapped Holes and How They Can Be Controlled
}

\author{
David L. Griscom \\ Impact Glass Research International, San Carlos, SON, Mexico \\ Correspondence should be addressed to David L. Griscom; david_griscom@yahoo.com
}

Received 9 May 2012; Accepted 19 October 2012

Academic Editor: Robert McLeod

Copyright (C) 2013 David L. Griscom. This is an open access article distributed under the Creative Commons Attribution License, which permits unrestricted use, distribution, and reproduction in any medium, provided the original work is properly cited.

\begin{abstract}
The natures of most radiation-induced point defects in amorphous silicon dioxide $\left(a-\mathrm{SiO}_{2}\right)$ are well known on the basis of 56 years of electron spin resonance (ESR) and optical studies of pure and doped silica glass in bulk, thin-film, and fiber-optic forms. Many of the radiation-induced defects intrinsic to pure and B-, Al-, Ge-, and P-doped silicas are at least briefly described here and references are provided to allow the reader to learn still more about these, as well as some of those defects not mentioned. The metastable self-trapped holes (STHs), intrinsic to both doped and undoped silicas, are argued here to be responsible for most transient red/near-IR optical absorption bands induced in low-OH silica-based optical fibers by ionizing radiations at ambient temperatures. However, accelerated testing of $a-\mathrm{SiO}_{2}$-based optical devices slated for space applications must take into account the highly supralinear dependence on ionizing-dose-rate of the initial STH creation rate, which if not recognized would lead to false negatives. Fortunately, however, it is possible to permanently reduce the numbers of environmentally or operationally created STHs by long-term preirradiation at relatively low dose rates. Finally, emphasis is placed on the importance and utility of rigorously derived fractal-kinetic formalisms that facilitate reliable extrapolation of radiation-induced optical attenuations in silica-based photonics recorded as functions of dose rate backward into time domains unreachable in practical laboratory times and forward into dose-rate regimes for which there are no present-day laboratory sources.
\end{abstract}

\section{Introduction}

Optical fibers and metal-oxide-semiconductor (MOS) devices based on amorphous forms of $\mathrm{SiO}_{2}\left(a-\mathrm{SiO}_{2}\right)$ are components of many photonic devices and systems that require hardness against nuclear and/or space radiations. Development of radiation-hardened optical fibers based on glassy silica, as well as MOS devices with amorphous $\mathrm{SiO}_{2}$ gate insulators, is dependent on a fundamental understanding of radiation-induced defect formation in the $a-\mathrm{SiO}_{2}$ component. The multitude of relevant radiation damage processes are schematically illustrated in Figure 1, which is taken from [1] where these processes are discussed in considerable detail. The present paper will limit its focus to the natures of the radiation-induced point defects-also termed "color centers"- that are known to absorb light in the wavelength range $\sim 500$ to $\sim 2000 \mathrm{~nm}$ in silica-based optical fibers and other photonic devices. A concise review of radiolytic trapped-oxide charges in $a$ - $\mathrm{SiO}_{2}$-based MOS structures and their relation to interface-state formation can be found in [2].

The molecular-scale structures of those point defects that are paramagnetic (i.e., possessing an unpaired electron) have been determined primarily by the technique of electron spin resonance (ESR) spectrometry. The most commonly measured ESR parameters are the $g$ values and hyperfine coupling constants, which will be mentioned in passing below but will not be defined here. Rather, the reader is referred to [3] for the meanings of these terms, as well as a highly condensed review of the theory and application of ESR to both insolating crystals and glasses, and/or to [4] for a more comprehensive review of both the theory and practice of ESR 
I

Irradiation
II

Prompt occurrences
III

Excited state relaxation, recombination

UV light

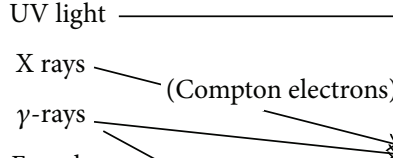

Fast electrons

Neutrons < (Secondary electrons)

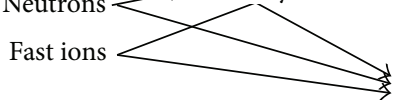

IV

Carrier trapping, defect formation

$\rightarrow$ Photolytic defects
V

Diffusion-limited reactions

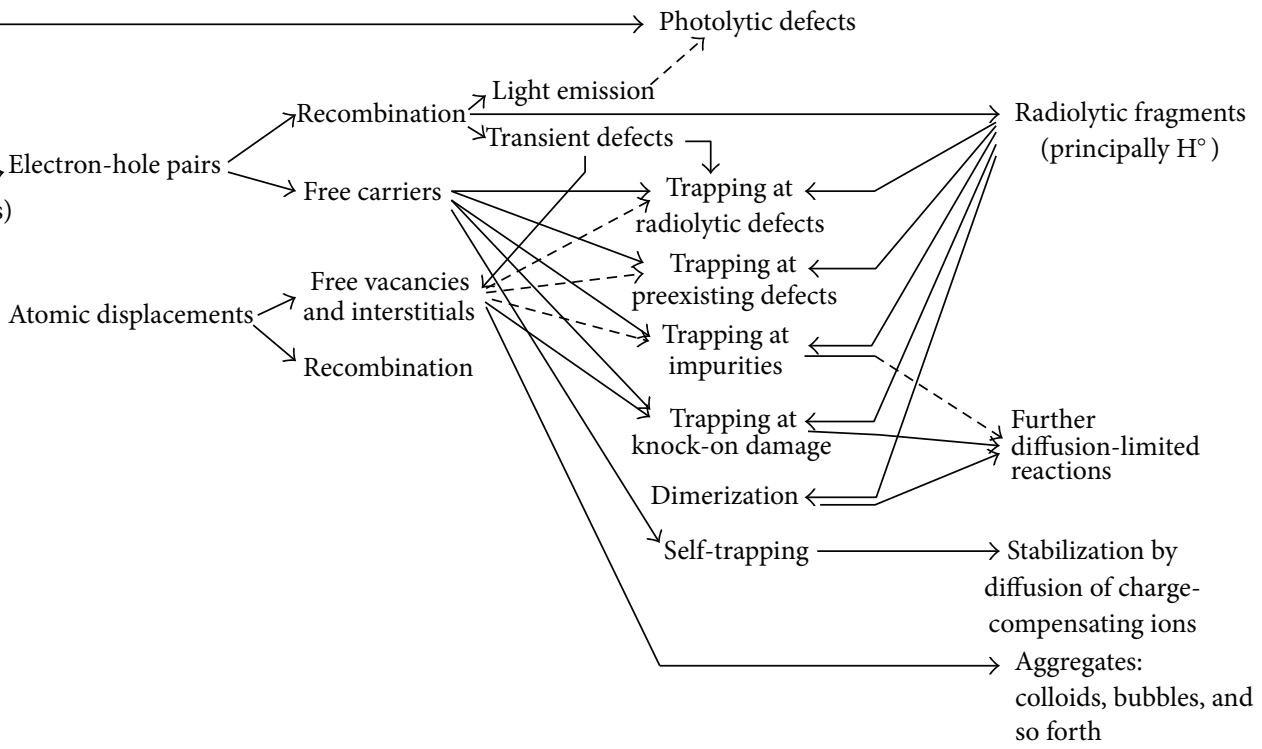

FIGURE 1: Modes of defect formation in insulators subjected to various types of ionizing radiations and/or particles of sufficiently high energy to create "knock-on" damage. See [1] for discussions of the indicated processes.

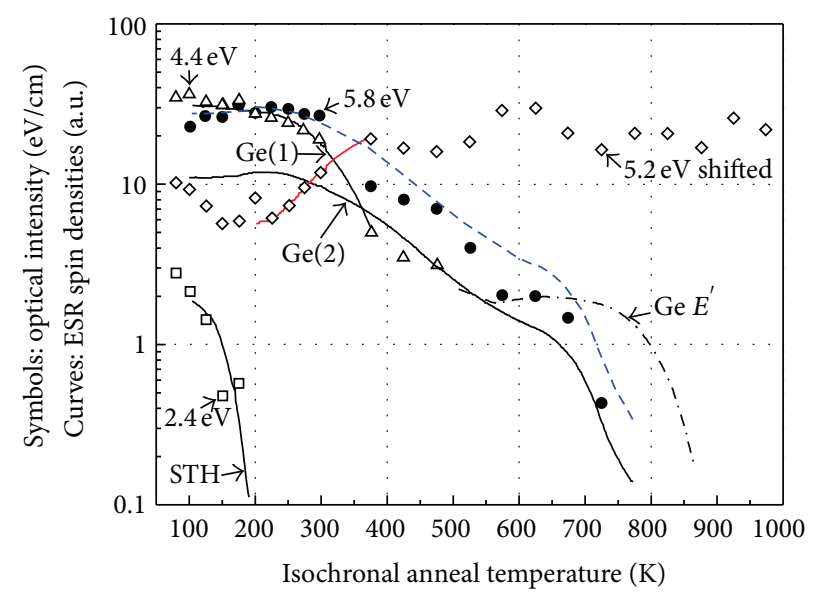

FIGURE 2: ESR-determined number densities (bold curves, relative units) and independently determined optical-band intensities (symbols, $\mathrm{eV} / \mathrm{cm}$ ) for X-ray-induced defect centers in separate samples of a Ge-doped-silica fiber-optic perform following irradiations to the same dose at 100 and $77 \mathrm{~K}$, respectively, and subsequent 5-minute isochronal anneals to the higher temperatures. (The ESR data were also recorded at discrete temperatures but are displayed here as continuous curves as an aid to the eye). It is seen here that the self-trapped holes (STHs) and the $\mathrm{Ge}(1)$ trapped-electron centers correlate well with optical absorption bands centered near 2.4 and $4.4 \mathrm{eV}$, respectively (and have identical oscillator strengths $[5,6]$ ). The upshifted $\mathrm{Ge}(2)$ number-density curve (dashed blue curve relating to Ge(2)'s higher oscillator strength) strongly matches the $5.8 \mathrm{eV}$ optical data below $300 \mathrm{~K}$ and is cryptically correlated with those data above $300 \mathrm{~K}$. The diamonds, representing a 5.2-eV band not associated with any ESR-detectable defect, are shown here displaced upward by a factor of 2.4 from their originally recorded optical intensities in order to discover their perfect match with the red curve in the range $200-370 \mathrm{~K}$, which comprises the sum of the changes of the $\mathrm{Ge}(1)$ and $\mathrm{Ge}(2)$ number densities in the range $200-370 \mathrm{~K}$ multiplied by negative 0.5 . This figure-adapted from [5] - was recently published in [6], where full explanations of the meanings and implications of these data can be found.

as applied to paramagnetic ions and radiation-induced point defects in (mostly silica-based) oxide glasses.

The associations of ESR-determined defect-center structures with specific optical absorption bands are generally established by ESR-optical correlations obtained, for example, by means of postirradiation isochronal thermal annealing experiments. Figure 2 provides an example of such a parallel set of ESR and optical isochronal anneal sequences 
recorded for a germanium-doped silica glass initially $\mathrm{x}$ irradiated at $\sim 100 \mathrm{~K}$ and annealed for 5 minutes at each sequence of higher temperatures $[5,6]$.

During the past half century many trapped-hole-type point defects in pure silicas have been identified by ESR (see, for example, [4]), in most cases unambiguously. (It should be noted however that silicas containing minor amounts of technological impurities such as $\mathrm{OH}, \mathrm{CO}, \mathrm{Cl}$, or $\mathrm{O}_{2}$ are often termed "pure," whereas these impurities frequently take part in the formation of defect centers extrinsic to the pure glass.) By contrast, many of the counterpart trapped-electron-type defects in pure silicas have historically appeared to be ESR silent. Very recently, I reviewed in considerable detail what is presently known about radiation-induced trapped-electron centers in both pure and $\mathrm{B}-, \mathrm{Al}-, \mathrm{Ge}-$, and P-doped silica glasses [7]. Among many other conclusions in [7], I was forced to reject and to replace certain models that I myself had posited earlier $[4,8]$ for radiation-induced defects in otherwise high-purity silicas containing high concentrations of chloride ions.

\section{What We Know for Certain about Point Defects in Glassy Silica}

2.1. Pure Silica. Among the best understood intrinsic defects in glassy silica is a family of oxygen-vacancy defects termed $E^{\prime}$ centers [9], which have been found to occur in a number of distinctly different variations termed $E_{\alpha, \beta, \gamma, \text { and } \delta}^{\prime}$ (e.g., $[8,10-13])$. Until very recently all of these were regarded as trapped-hole centers. However, there is substantial evidence $[7,12]$ that the low-temperature version of $E_{\alpha}^{\prime}, E_{\alpha L T}^{\prime}$ (nomenclature proposed in [7]) may be a trapped-electron center, whereas the high-temperature version of $E_{\alpha}^{\prime}, E_{\alpha H T}^{\prime}$ has been unambiguously shown to be a trapped hole center [13]. The historical confusion owes to both $E_{\alpha}^{\prime}$ versions sharing approximately the same $g$ values-which is a necessary, but far from sufficient, condition for their being sterically and electronically identical.

Still, the majority of all $E^{\prime}$ centers result from trapping of holes $\left(h^{+}\right)$at a neutral oxygen vacancies in pure-silicaglass networks otherwise comprising $\mathrm{Si}_{4}$ tetrahedra linked at the corners; (the notation " $\varnothing$ " indicates that in a hypothetically defect-free silica glass each oxygen, $\mathrm{O}$, forms a bridge between, and is thus shared by, the central Si and one of its four nearest-neighbor silicons). The most famous exception is $E_{\delta}^{\prime}$, which was originally proposed to involve an unpaired electron delocalized over four silicons [8], has since been widely argued by theorists to involve just two silicons, but has finally been experimentally proven to involve at least four virtually equivalent silicon neighbors and possibly five [14]. Some other recently proposed exceptions involve $E_{\gamma}^{\prime}$ centers induced in silicas with high $\mathrm{Cl}$ contents (now regarded in [7] to have been misinterpreted in [8]) and $E^{\prime}$-type centers associated with oxygen "pseudo vacancies," to be explained in Section 2.2.

In the simplest case of preexisting neutral oxygen mono-vacancies in the pure-silica glass structure, the radiolytic process of $E^{\prime}$ center creation can be represented as

$$
[\equiv \mathrm{Si}: \mathrm{Si} \equiv]^{0}+h^{+} \longrightarrow\left[\equiv \mathrm{Si} \bullet{ }^{+} \mathrm{Si} \equiv\right]^{+},
$$

where "三” represents bonds to 3 bridging oxygens, “ $\varnothing$ ", in the glass network, ":" represents a pair of electrons shared between the two silicons on opposite sides of the vacancy, and "." is an unpaired electron localized in a dangling $s p^{3}$ orbital of a single silicon, as determined by ESR studies of irradiated samples. Most commonly, the defect structure “ $\equiv$ Si $\bullet "$ on the right-hand side of (1) is an $E_{\gamma}^{\prime}$ center although in certain cases it may be an $E_{\alpha}^{\prime}$ or $E_{\beta}^{\prime}$ center signaled by small but easily discernable differences between their respective spin Hamiltonian parameters $[3,4,13]$ and often depending on their respective modes of creation and/or thermal stabilities $[8,10-13]$. In general, these variants are believed to correspond to different distortions or relaxations of the structure $\equiv \mathrm{Si} \bullet$ and/or the structure of the surrounding glass in which this unit is embedded (see especially [11]).

In addition there are nonbridging-oxygen hole centers (NBOHCs: “三Si-O•", see, e.g., [4])), peroxy radicals (PORs: "三Si-O-O•", see, e.g., [4]) and two types of self-trapped holes $\left(\mathrm{STH}_{1}\right.$ and $\mathrm{STH}_{2}[15,16]$, the structures of which will be elucidated in Section 3). The literature is enormous, but references $[1,4,12]$ are recommended entry points.

2.2. Doped Silicas. The best understood defects in doped glassy silica are those for which $\mathrm{Si}$ is substituted by $\mathrm{B}$, $\mathrm{Al}, \mathrm{Ge}$, or $\mathrm{P}$. This is because the radiation-induced the aluminum-oxygen hole center (Al-OHC), the so-called $\mathrm{Ge}(1)$ and $\mathrm{Ge}(2)$ centers, and the $\mathrm{P}_{2}$ trapped-electron center in the respectively-doped glasses have each been shown to be virtually identical with a doppelganger in similarly-doped crystalline $\alpha$ quartz, as discussed in detail in [7]. These $\alpha$ quartz doppelgangers are unambiguously understood thanks to tedious, highly specialized, and meticulously performed, single-crystal ESR angular dependence studies carried out by John Weil and his students and colleagues (see [17] for a listing of reviews). It should be noted that the boron-oxygen hole center (B-OHC) has no doppelganger in $\alpha$ quartz; however it is isomorphous with the Al-OHC.

2.2.1. Ge-Doped Silica. As seen in Figure 2, the correspondences of the ESR data (curves) and optical measurements (data points) show that the $\mathrm{Ge}(1)$ and $\mathrm{Ge}(2)$ centers in Gedoped silica glass have optical absorption bands at $4.4 \mathrm{eV}$ and $5.8 \mathrm{eV}$, respectively.

Of particular importance to understanding the natures of these $\mathrm{Ge}(1)$ and $\mathrm{Ge}(2)$ defects are the remarkable interrelationships (described in greater detail in $[6,7]$ ) between the $\mathrm{Ge}(1)$ and $\mathrm{Ge}(2)$ centers in Ge-doped silica glass and the $\mathrm{Ge}(\mathrm{II})$ and $\mathrm{Ge}(\mathrm{I})$ centers, respectively, in $\alpha$ quartz.

(A) Given that the $\mathrm{Ge}(1)$ center in Ge-doped silica glass $[5-7,18]$ is characterized by virtually the same $g$ values and mean hyperfine coupling constant as those of the Ge(II) center in quartz [19, 20], it must be concluded that (i) " $\alpha$-quartz-crystal-like" $\mathrm{Ge}_{4}$ 
tetrahedra preexist in the glass and (ii) $\mathrm{Ge}(1)$ shares the $\mathrm{Ge}(\mathrm{II})$ property of being an electron trapped in a Ge $s p$ orbital parallel to the twofold axis of symmetry of this tetrahedron.

(B) Given that the $\mathrm{Ge}(\mathrm{I})$ center in $\alpha$ quartz $[19,20]$ is characterized by $g$ values only slightly different from, and mean hyperfine coupling constant virtually identical to, those of the $\mathrm{Ge}(2)$ center in silica glass $[5-7,18]$ - and it is known $[19,20]$ that $\mathrm{Ge}(\mathrm{I})$ is an electron trapped in symmetry-breaking orbitals perpendicular to the twofold axis a $\mathrm{Ge}_{4}$ tetrahedron in the $\alpha$-quartz lattice (thus making it an energetically different state of the same defect responsible for $\mathrm{Ge}(\mathrm{II})$ [19]) - it must be concluded that (i) $\mathrm{Ge}(\mathrm{I})$ is a "glass like" defect even though it occurs in perfect crystal and (ii) the "default" interpretations of $\mathrm{Ge}(1)$ and $\mathrm{Ge}(2)$ are that they are two energetically different states of the same defect in Ge-doped silica glass.

Notwithstanding insights (A) and (B) above, observed variations in the $\mathrm{Ge}(1)$-to- $\mathrm{Ge}(2)$ concentration ratios at room temperature continue to convince some researchers that $\mathrm{Ge}(1)$ and $\mathrm{Ge}(2)$ cannot be two energetically different states of the same precursor (e.g., [21]). For example, in Figure 2 the $\mathrm{Ge}(1): \mathrm{Ge}(2)$ ratio is seen to be $\sim 2: 1$ after $\mathrm{x}$ irradiation at $100 \mathrm{~K}$ and a 5-min warming at $300 \mathrm{~K}$ [6], whereas this ratio has been found in [21] to be $0.8: 1$ for $\mathrm{GeO}_{2}$ doped silica optical fibers and preforms $\gamma$-irradiated at room temperature and stored at ambient temperatures for a full month before recording the data. However, this is hardly a serious contradiction, given that in Figure 2 it is seen that a further 5 -min anneal at $370 \mathrm{~K}$ also results in a $\mathrm{Ge}(1): \mathrm{Ge}(2)$ ratio of $\sim 0.8: 1$.

Here below I will summarize and analyze a very different example-one that cannot be dismissed without further consideration: Nagasawa and coworkers [22] provided striking evidence of selective destruction of $\gamma$-ray-induced $\mathrm{Ge}(2)$ centers-but not $\mathrm{Ge}(1)$ centers-in Ge-doped-silicacore optical fibers by postirradiation ambient-temperature in-diffusion of molecular hydrogen. They also reported a linear relationship between (i) the numbers of $\mathrm{Ge}(2)$ centers recorded by ESR in five different samples immediately following $\gamma$-irradiation and (ii) the numbers of $[=\mathrm{Ge}-\mathrm{H}]^{0}$ defects subsequently created in these same samples by identical $\mathrm{H}_{2}$ treatments.

The $\left[=\mathrm{Ge}^{\bullet}-\mathrm{H}\right]^{0}$ defect, commonly termed the $\mathrm{H}(\mathrm{II})$ center, results when a charge-neutral twofold-coordinated germanium $[=\mathrm{Ge}:]^{0}$ - commonly termed the Germanium Lone Pair Center $\left(\mathrm{GLPC}^{0}\right)$-reacts with a neutral hydrogen atom, $\mathrm{H}^{0}$, a process that has been extensively studied by Bobyshev and Radtsig on the surfaces of Ge-doped silica glasses [23]. (Confirmation of the structure of the analogous $\left[=\mathrm{Si}{ }^{\circ}-\mathrm{H}\right]^{0}$ defect in pure bulk silica, denoted H(I), is given in [24].)

In order for $\mathrm{H}$ (II) centers to have formed in Nagasawa et al's [22] bulk glasses, both of the following processes must have taken place [23]: (i) two Ge- $\varnothing$ bonds must have been broken at each of an equal number of tetrahedrally coordinated germanium sites and (ii) the introduced molecular $\mathrm{H}_{2}$ must have been "cracked" into a pair of free hydrogen atoms. One possible cracking site could have been nonbridgingoxygen hole centers (NBOHCs) [25], if any were present. Conceivably, however, $\mathrm{H}_{2}$ might have been cracked in the process of destroying $\mathrm{Ge}(2)$ centers:

$$
\left[\mathrm{Ge}_{4} \bullet\right]_{2}{ }^{-}+\mathrm{H}_{2} \longrightarrow\left[\mathrm{Ge} \varnothing_{4} \mathrm{H}\right]_{2}{ }^{-}+\cdot \mathrm{H}^{0}
$$

where " $\left[\mathrm{Ge} \varnothing_{4}\right]$ " denotes a substitutional germanium, “॰” a trapped electron, the superscript "-" a negative electrostatic charge, and the subscript " 2 " a Ge(2)-type trapped-electron on the left-hand side of the reaction... and the " $H$ " on the right-hand side is an $\mathrm{H}^{0}$ bonded to this $\mathrm{Ge}(2)$-type orbital.

Cracking reactions of $\mathrm{H}_{2}$ dissolved in silica glass can be determined by its diffusion coefficient alone if the reaction coefficient pertaining to the entity upon which it cracks is more rapid than the diffusion time (an explicit example of this is given in [25]). Conversely, the reaction could be greatly slowed if the reaction coefficient should happen to be much slower than the diffusion coefficient. Thus, if $\mathrm{Ge}(1)$ and $\mathrm{Ge}(2)$ are "two energetically different manifestations of the same defect" - as it certainly appears that they are-it is not at all unreasonable to suggest from the results of [22] that $\mathrm{Ge}(1)$ has a much slower reaction coefficient for a cracking $\mathrm{H}_{2}$ than does $\mathrm{Ge}(2)$.

Apropos, by tracing the ESR intensities of $\mathrm{Ge}(1)$ and $\mathrm{Ge}(2)$, together with the $5.2-\mathrm{eV}$ optical intensity of $\mathrm{GLPC}^{0}$ in the range $\sim 200$ to $370 \mathrm{~K}$ in Figure 2, it was determined [6] that $\mathrm{GLPC}^{0} \mathrm{~s}$ had trapped a number of holes equal to the combined number of electrons trapped at $\mathrm{Ge}(1)$ and $\mathrm{Ge}(2)$ sites. However, the number density of hole-trapping GLPC $^{0} s$ deduced in [6] was only $50 \%$ of this number [6] -thus proving that $\mathrm{GLPC}^{0}$ s stably trap holes only in pairs (thereby becoming $\mathrm{GLPC}^{2+} \mathrm{s}$ ). Because they possess no unpaired electrons, both GLPC ${ }^{0}$ and GLPC $^{2+}$ are ESR silent. Moreover, it is empirically apparent that neither one has a strong optical band in the range 1 to $6 \mathrm{eV}[5,6]$.

2.2.2. Boron- and Aluminum-Doped Silicas. Boron does not substitute in $\alpha$ quartz. However, in a $\gamma$-irradiated binary $\mathrm{B}_{2} \mathrm{O}_{3}-3 \mathrm{SiO}_{2}$ glass, borons substituted for silicons were found to trap holes to form boron-oxygen hole centers (B-OHCs) [26]. This result is in perfect analogy to the Al-OHCs reported to occur in both Al-containing quartz [27] and Aldoped silica glass [28]. By contrast, trapped-electron-type B$E^{\prime}$ centers [26] and Al- $E^{\prime}$ centers (reported by Brower in [29] and reviewed in [7]) are created upon irradiation of a binary $\mathrm{B}_{2} \mathrm{O}_{3}-3 \mathrm{SiO}_{2}$ glass and an Al-doped silica, respectively, whereas no counterparts to either of these trapped-electron defects exist in $\alpha$ quartz.

In [26] it was proposed that the radiation-induced $\mathrm{B}-E^{\prime}$ centers $[\equiv \mathrm{B} \bullet]^{-}$in the binary $\mathrm{B}_{2} \mathrm{O}_{3}-3 \mathrm{SiO}_{2}$ glass result from electron trapping at the sites of preexisting oxygen "pseudo vacancies," diagrammed as $\left[\equiv \mathrm{B}{ }^{+} \mathrm{Si} \equiv\right]^{+}$. This model was extended in [7] to apply also to the Al- $E^{\prime}$ centers $[\equiv \mathrm{Al} \bullet]^{-}$in Al-doped silica. Thus

$$
\left[\equiv \mathrm{Al}{ }^{+} \mathrm{Si} \equiv\right]^{+}+e^{-} \longrightarrow\left[\equiv \mathrm{Al} \bullet^{-}{ }^{+} \mathrm{Si} \equiv\right]^{0} .
$$


Note the similarity of the right-hand sides of (1) and (3). However, the paramagnetic defect on the right of (1) is a positively charged trapped-hole center, whereas the paramagnetic defect on the right of (3) is a charge-neutral trappedelectron center, as discussed in greater detail in [7]. Note that in this model the unirradiated glasses must maintain charge neutrality by assuring that the numbers of negatively charged substitutional $\left[\mathrm{B} \emptyset_{4}\right]^{-}$and $\left[\mathrm{Al} \emptyset_{4}\right]^{-}$tetrahedra exactly equal the numbers of $\left[\equiv \mathrm{B}{ }^{+} \mathrm{Si} \equiv\right]^{+}$and $\left[\equiv \mathrm{Al}{ }^{+} \mathrm{Si} \equiv\right]^{+}$"pseudo vacancies," respectively.

It has recently been shown [30] that subband-gap-excited luminescence bands at 2.8 and $4.4 \mathrm{eV}$ recorded for a silica sample to which was added $0.015 \mathrm{wt} \%$ elemental silicon (introducing true oxygen vacancies) are virtually identical to those recorded for silica doped to the same degree with $\mathrm{Al}_{2} \mathrm{O}_{3}$. This particular luminescence is unambiguously attributed to charge-neutral twofold-coordinated silicons ( $[=\mathrm{Si}:]^{0}$, an ESR-silent oxygen-vacancy defect; see [7] and references therein), and its strength in the $0.015 \mathrm{wt} \%$-Sidoped sample is $\sim 50$ to 100 times greater than that of undoped silica [30]. Therefore, the results of the experiment of [30] imply that a commensurate degree of $\mathrm{Al}_{2} \mathrm{O}_{3}$ doping somehow creates the same high number and type of oxygen vacancies (specifically involving twofold coordinated silicons) as does doping with elemental Si. The only conceivable way that this could happen must somehow relate to the presence of Al "pseudo vacancies" $[7,26]$ in the as-quenched alumina-rich glass, that is, in the form of $\left[\equiv \mathrm{Al}{ }^{+} \mathrm{Si} \equiv\right]^{+}$units. Although the explanation for the appearances of twofoldcoordinated silicons under these conditions is necessarily more complicated (as is also the case of silica doped only with elemental $\mathrm{Si}$ ), a possible model explaining the results of both of these cases is proffered in [7].

\section{Space Applications Narrow the Subject Mostly to Self-Trapped Holes}

The facts are that (i) the most radiation-hard nonlaser silicabased optical fibers employ little or no cationic dopants, (ii) the commonly used fluorine dopants appear not to take part in color-center formation [31] (though chloride impurities are problematic [31]), and (iii) for dose rates $\sim 6 \mathrm{~Gy} / \mathrm{s}$ the transient optical absorption near $660 \mathrm{~nm}$ induced at short times in low-OH pure-silica fibers (due to STHs; see below) is $\sim 3$ orders of magnitude greater than that of the concomitantly induced $620 \mathrm{~nm}$ band of (nondecaying) NBOHCs following a total dose of $10^{7} \mathrm{~Gy}$ [31]. It therefore follows that the true "elephant in the room" with respect to nuclear and space applications of glassy silica would seem to be the STHs [15, 16]. Metastable STHs are always created in low-OH glassy silica by ionizing radiation, so long as there are no strongly competing hole-trapping dopants or impurities present. As will be explained in greater detail in Section 3.5, STHs in high$\mathrm{OH}$ silicas are instantly quenched by reaction with atomic hydrogen released by radiolysis of $\mathrm{OH}$ groups $[2,32,33]$.

The discovery and ESR characterization of the STHs are extensively discussed in $[15,16]$, so most of the details will not be reprised here. However, it can be stated that two

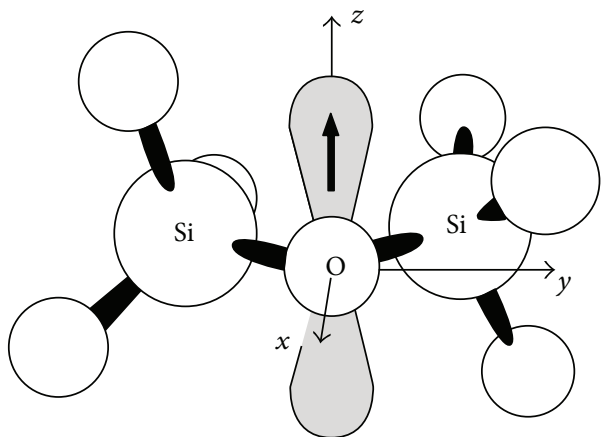

(a)

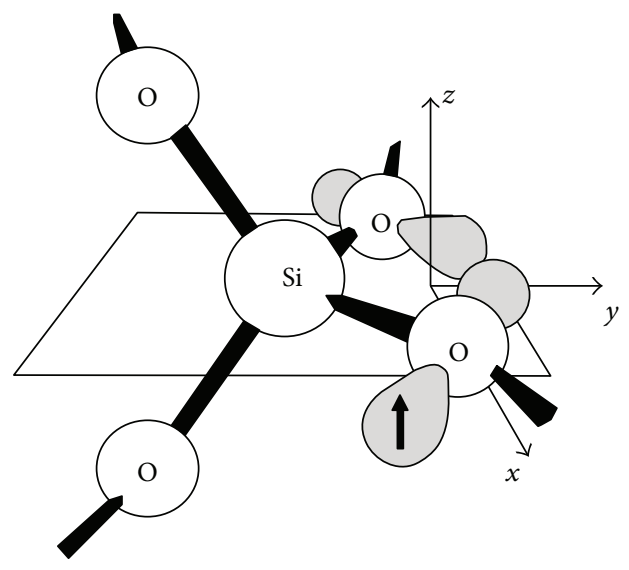

(b)

Figure 3: Models for self-trapped holes in silica-based glasses: (a) $\mathrm{STH}_{1}$ and (b) $\mathrm{STH}_{2}$. These structures were deduced experimentally on the basis of a highly detailed ESR study [15] involving both $g$-value distributions and ${ }^{29} \mathrm{Si}$ hyperfine splittings (and theories thereof) and have since been successfully calculated by $a b$ intio methods, for example, $[35,36]$. Here, the shaded "balloons" represent the orbitals of the unpaired electron spins (denoted by vertical arrows).

distinct variants of STHs, termed $\mathrm{STH}_{1}$ and $\mathrm{STH}_{2}$, have been identified in irradiated silica glasses as the local structures portrayed in Figure 3. In principle, the potential hole trapping sites leading to $\mathrm{STH}_{1}$ formation can be virtually anywhere in the glass network. By contrast, the sites that become $\mathrm{STH}_{2} \mathrm{~s}$ upon hole trapping are likely to be relatively rare, since these precursor sites have been shown $[15,16]$ to have $\alpha$-quartz-like local structure, whereas a comparison of X-ray-diffraction radial-distribution functions of glassy silica with those the $\alpha$ quartz, cristobalite, and tridymite crystalline polymorphs of $\mathrm{SiO}_{2}$ has shown quartz to be the least similar to structure to silica glass (correlation coefficient of only 0.26 , versus 0.69 and 0.82 for cristobalite and tridymite, respectively [34]).

The ideal "defect-free" [37] structures of inorganic glasses are best determined by means of carefully controlled X-ray and neutron diffraction methods followed by data analyses governed by a branch of materials science termed "amorphography" [38]. It is stated in [37] that

"...since the ideal structure (of an inorganic glass) is disordered, departures from normality 
can occur in the direction of both decreased and increased order, the former leading to what are commonly known as defects."

However, in light of the quartz-like $\mathrm{Ge}(1)$ and $\mathrm{Ge}(2)$ trapped electron centers in Ge-doped silicas discussed in Section 2.2 and the quartz-like precursor structures deduced for $\mathrm{STH}_{2}$ in pure silica glasses $[15,16]$, it appears that departures from normality in the direction of increased order can also serve as electron- or hole-trapping sites which are termed defects in such silica-based glasses when they trap electrons or holes loosed by ionizing radiations.

3.1. Optical Spectra of Self-Trapped Holes. Self-trapped holes in silica were first identified in bulk silica glasses by ESR studies, the initial results of which I reported in 1989 [39]. The first STH-related optical band was reported practically simultaneously by Chernov et al. [40] and pertained to low-OH, puresilica-core fibers irradiated at $77 \mathrm{~K}$. This band, termed by its discoverers "low-temperature infrared absorption (LTIRA)" [40], consisted of a broad absorption beginning in the visible and increasing with increasing wavelength until peaking near $1800 \mathrm{~nm}$. Its isochronal annealing characteristics were found to be very similar to a component of trapped positive charge in an $a-\mathrm{SiO}_{2}$ thin film as reported by Harari et al. [41]. However, to my knowledge no follow-up studies of $1800 \mathrm{~nm}$ band have since been published.

Similarly, soon after completing my main paper on the ESR-determined properties of STHs [15] for publication in the proceedings of the International Seminar Point Defects in Glasses (Riga, Latvia, July -August, 1991), my activities at the Naval Research Laboratory (NRL) were redirected toward radiation hardening of fiber optics for ITER diagnostics under a contract from the U.S. Department of Energy (DOE). Due to this redirection, I found no opportunity to look for optical manifestations of STHs in bulk silicas. Indeed, I had nearly forgotten about STHs when five years later I began to think that the intense absorption bands at 660 and $760 \mathrm{~nm}$ (originally reported by Nagasawa and coworkers [42, 43]) that leaped up in my aluminum-jacketed low-OH pure-silicacore and F-doped-silica-core test fibers immediately upon inserting the sample coils into the NRL "swimming pool" $\gamma$ ray source might be due to STHs $[44,45]$.

It was another five years later, and a year after my January 2001 retirement from NRL, when I finally devised a means to obtain isochronal anneal data for the 660 and $760 \mathrm{~nm}$ fiberoptic bands following $\gamma$-irradiation at $77-\mathrm{K}$. And I managed to carry out the experiment during the final two weeks of my 10 month invited professorship of research at Tokyo Institute of Technology. Then two more years passed before I became sufficiently inspired to analyze those very convoluted data sets and publish the results in [46]. These results indeed agreed quite well with my previously published isochronal anneal curves for $\mathrm{STH}_{1}$ and $\mathrm{STH}_{2}$ in bulk silica $[15,16,39]$, as well as with Harari et al's trapped positive charge curve [41].

In the meantime, Sasajima and Tanimura [47] had reported both ESR and dichroic optical spectra of a well selected suite of bulk silica samples subjected to 1-Mev, 20ns-duration electron pulses at $77 \mathrm{~K}$. They reported that their

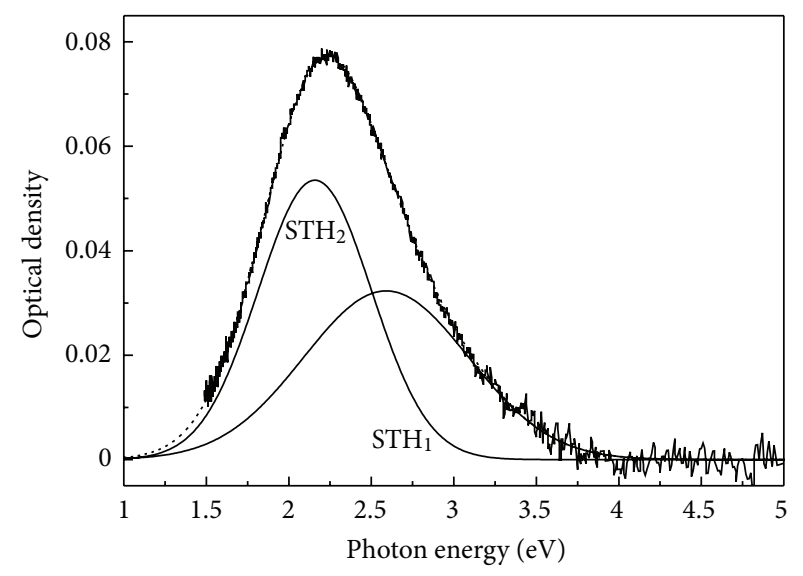

FIGURE 4: Optical bands of $\mathrm{STH}_{2}$ and $\mathrm{STH}_{1}$ induced in a low-OH, low-Cl bulk fused silica by pulsed electron irradiation at $77 \mathrm{~K}$. These bands were separated from a series of bands peaking at successively higher energies (not shown) by means dichroic red-light bleaching, and it was these dichroic bands (shown here) that correlated with the ESR spectra recorded for the very same samples. This figure is replotted from [47] using the original data and fitted curves kindly provided in digital form by Tanimura.

lowest-OH, lowest-Cl bulk samples yielded the strongest STH ESR signals. Notably, my lowest-OH, lowest-Cl optical fibers yielded the strongest 760 and $660 \mathrm{~nm}$ bands (1.63 and $1.88 \mathrm{eV}$, resp.,) during ambient-temperature $1.5 \mathrm{Mev}{ }^{60} \mathrm{Co} \gamma$ irradiation. However, I have never recorded ESR spectra for my irradiated fibers, whereas Sasajima and Tanimura unambiguously associated their induced optical bands at 2.16 and $2.60 \mathrm{eV}$ (Figure 4) with the classical [15] ESR signals of $\mathrm{STH}_{2}$ and $\mathrm{STH}_{1}$, respectively, recorded for the very same samples as used for their optical studies. So if I have correctly interpreted the 1.63 and $1.88 \mathrm{eV}$ bands induced in my puresilica core fibers $[16,31,44-46]$ as being due to STHs, the natures of these optical-fiber STHs must differ considerably from those in bulk silica.

In my recent review article on STHs [16] I cited data in the literature for STH spin densities per unit dose increasing with increasing fictive temperature and remarked that fictive temperatures of silica-core optical fibers are much higher than those of bulk glasses, thus invoking fictive temperature as a possible reason for the difference between 2.16 and $2.60 \mathrm{eV}$ STH optical bands in bulk silica [47] and the 1.63 and $1.88 \mathrm{eV}$ bands in silica fibers [31, 44-46]. However, in retrospect it might also be considered that the structures of silica glasses drawn into fibers surely have residual uniaxial strains superposed on the $\mathrm{SiO}_{2}$ random network. And these strains would affect the $\mathrm{Si}-\mathrm{O}-\mathrm{Si}$ bond angles anisotropically, thereby changing the properties of STHs created therein relative to those in isotropic bulk glasses studied under similar experimental conditions.

3.2. Yet Another Difference between the Optical Spectra of Self-Trapped Holes in Bulk and Optical-Fiber-Form Silicas. Sasajima and Tanimura [47] determined that the $\mathrm{STH}_{1}$ absorption band peaking at $2.60 \mathrm{eV}$ in bulk silica glass, though 
Gaussian in shape, is homogeneously broadened-meaning that bleaching just a small part of the band destroys the entire band rather than burning a hole in it. Thus, at least in the case of the $\mathrm{STH}_{1}$ band, the bulk-silica bands cannot be decomposed into sums of component subbands. By contrast, as illustrated in Figure 5, the putative STH bands including prominent peaks at $1.63 \mathrm{eV}(760 \mathrm{~nm})$ and $1.88 \mathrm{eV}(660 \mathrm{~nm})$ recorded for irradiated low-OH F-doped and pure-silica core fibers [44] are clearly much narrower and more numerous than those in bulk silicas [47]. The reasons for this remain unknown, but are surely related to one or more of the issues raised in Section 3.1.

3.3. Growth and Decay Kinetics of Self-Trapped Holes in Pure-Silica-Core Optical Fibers. Figure 6 [44] illustrates the intensities at $760 \mathrm{~nm}$ of the spectra (including those of Figure 5(a)) recorded during in-the-dark ${ }^{60} \mathrm{Co} \gamma$-irradiation at $1 \mathrm{~Gy} / \mathrm{s}$, using the CCD-camera-based prism spectrometer described in [31] (light on for $\sim 2$ to $5 \mathrm{~s}$ per screen grab) at time intervals varying by factors of $\sim 3$ and ranging from $32 \mathrm{sec}$ to 24 days. This process was briefly interrupted to record ambient-temperature ex situ thermal bleaching and subsequent recovery when this Al-clad fiber coil was returned to its original position in the source [48]. The in situ optical bleach and recovery spike in this figure was taken from an earlier experiment using the same fiber type and radiation dose rate.

The crosses in Figure 6 represent a classical second-order kinetic fit to the data recorded at times above $10^{4} \mathrm{~s}$. Accepting this fit as the correct representation of reality, a $t^{-1}$ decrease in induced absorption is to be expected at still longer irradiation times, $t$. I later determined that this decline in induced loss during continued irradiation is permanent. Specifically, in [45] I found that upon reirradiation at $1 \mathrm{~Gy} / \mathrm{s}$ of a pure-silicacore fiber that 3 months previously had been subjected to the same dose rate for $10^{7} \mathrm{~s}$, the incremental optical absorptionversus-time curve was two orders of magnitude weaker at $t \sim 200 \mathrm{~s}$ than observed during the initial irradiation, $\sim 20$ times weaker than the original curve recorded near $10^{4} \mathrm{~s}$, and about one order of magnitude weaker at $10^{6} \mathrm{~s}$. Describing the same data from a different perspective, this fiber had been radiation hardened to such a degree by the original irradiation that the results of re-irradiation 3 months later at the same dose rate resulted in newly induced absorption that was generally less than the final value at the end of the first irradiation. Moreover, I discovered in [44] that this Radiation Stimulated Reconfiguration (RSR) process (a terminology that I introduced in [48]) is purely a function of time - not of dose-for dose rates ranging between $0.15 \mathrm{~Gy} / \mathrm{s}$ and $5.5 \mathrm{~Gy} / \mathrm{s}$.

One additional experiment reported in [45] involved pulling the irradiated sample coils out of the "swimming pool" $\gamma$-ray source, rapidly recording a spectrum at room temperature and immediately afterward thrusting the coil into liquid nitrogen and then recording a second spectrum. Taking the difference between these two spectra revealed the $77-\mathrm{K}$ spectrum to be characterized by (i) an added gray absorption, (ii) a shift of the principle peak position downward from $660 \mathrm{~nm}$ to $\sim 630 \mathrm{~nm}$, and (iii) a component

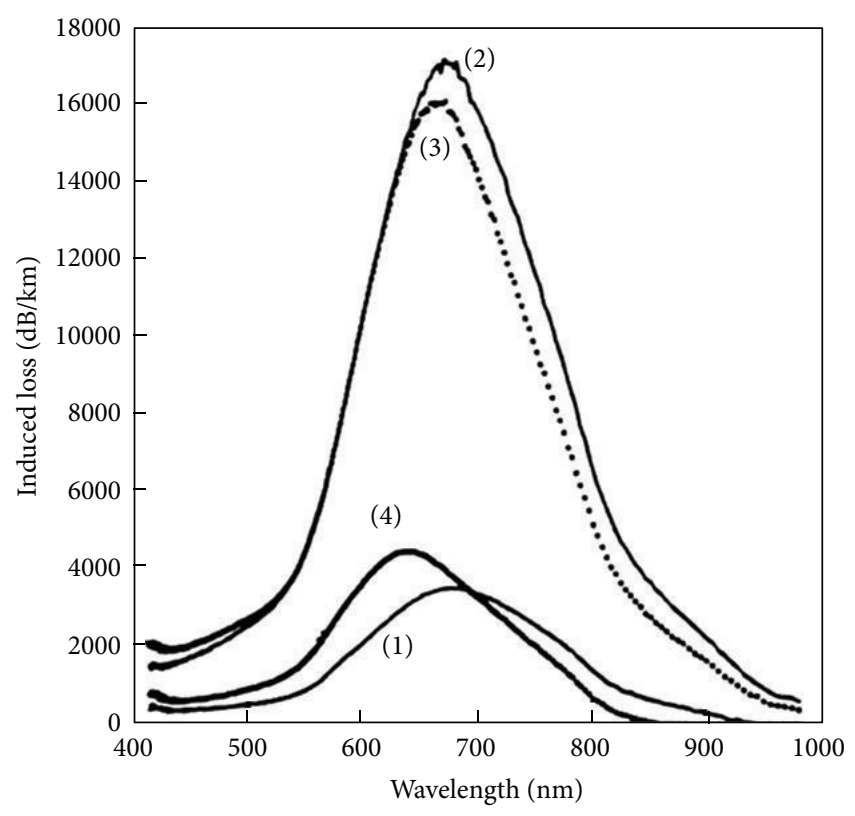

Dose $[\mathrm{Gy}(\mathrm{Si})]$ :
(1) 34
(3) $1.7 \times 10^{5}$
(2) 244
(4) $2.5 \times 10^{6}$

(a)

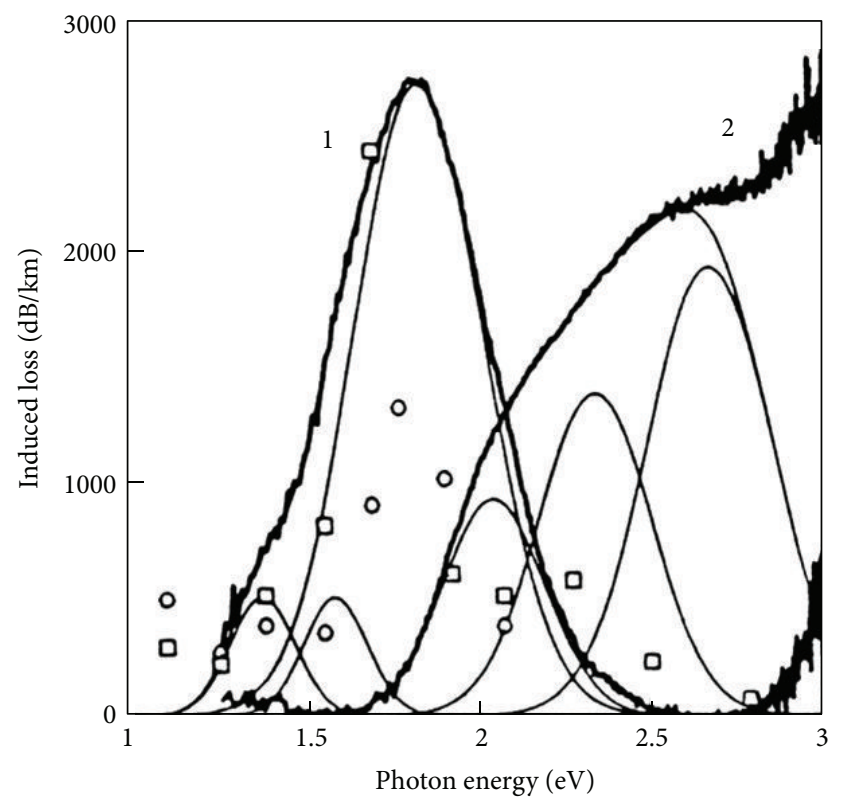

(b)

FIGURE 5: (a) Visible/near-IR spectra of a low-OH F-doped-silicacore optical fiber at selected times during continuous $\gamma$-irradiation at $1 \mathrm{~Gy} / \mathrm{s}$ in the dark. (b) A decomposition of similar spectra of a low-OH high-purity-silica-core fiber concomitantly irradiated and recorded under identical conditions. This decomposition was achieved by first separating the red/near-IR peaks (1) from the induced absorptions at higher energies (2) by means of cut-and-try subtractions of several members of the full set of recorded spectra, of which the four displayed in (a) are corresponding examples (adapted from [44]). Superposed circles and squares in (b) represent in arbitrary units optically stimulated release of trapped positive charge from an X-irradiated $a-\mathrm{SiO}_{2}$ thin film (data from [41]). 


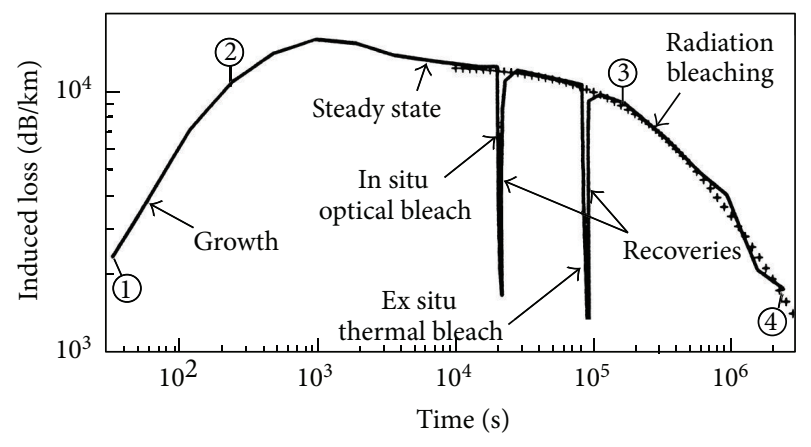

FIGURE 6: Kinetics of the $\gamma$-ray-induced optical absorption measured at $760 \mathrm{~nm}$ in an F-doped-silica-core, Al-jacketed optical fiber as a function of irradiation time at $1 \mathrm{~Gy} / \mathrm{s}$ at ambient temperature $(\sim 27 \mathrm{C})$ in the dark, except for $\sim 3$ seconds of probe light for each frame grab. The illustrated in situ optical bleach spike was taken from a separate experiment at the same dose rate and was "grafted" onto the present data for comparison purposes. Circled numbers 1 , 2,3 , and 4 correspond to the numbered spectra of Figure 5(a). Figure from [44].

monotonically increasing with increasing wavelength up to maximum value measurable at that time, $1000 \mathrm{~nm}$. I speculated in [45] that the latter may be the high-energy tail of Chernov et al.'s LTIRA (cf. Section 3.1). This speculation could be tested by repeating this experiment with an instrument capable of recording spectra out to $\sim 2000 \mathrm{~nm}$.

3.4. If STHs Are the Problem, Accelerated Testing Can Easily Lead to False Positives. Figure 7, adapted from [48], exhibits optical absorption data picked off at $900 \mathrm{~nm}$ from complete spectra of the type shown in Figure 5(a) recorded as functions of $\gamma$-irradiation time for two virgin lengths of fiber taken from the same spool of aluminum-clad, low-OH/low-Cl KS4V pure-silica-core optical fiber subjected to dose rates of $0.15 \mathrm{~Gy} / \mathrm{s}$ and $1.02 \mathrm{~Gy} / \mathrm{s}$. Note in Figure 7 the confluence of the two data sets (solid squares and circles) at times longer than $\sim 10^{6} \mathrm{~s}$. The large hollow symbols are not data points; rather they have been added to connect arbitrarily selected points on the two curves which share identical radiation doses. Clearly, if the $1.02 \mathrm{~Gy} / \mathrm{s}$ curve had been an accelerated test and $0.15 \mathrm{~Gy} / \mathrm{s}$ was the anticipated mission dose rate, the accelerated test would be seriously lying about the vulnerability of this fiber to mission conditions.

\subsection{Radiation Hardening by the Presence of Hydroxyl Groups} or Interstitial Hydrogen. In [33] the influence of pulsed xirradiation on the optical transmission of a pair of highpurity-silica-core optical fibers was investigated at room temperature. Transient exposures employed a $\sim 1 \mathrm{MeV}$ pulsed Xray generator with doses varying between 1 and $300 \mathrm{~Gy}\left(\mathrm{SiO}_{2}\right)$ and dose rates $>1 \mathrm{MGy} / \mathrm{s}$. One of these fibers had a high $\mathrm{OH}$ content and the other an extremely low $\mathrm{OH}$ content. Figure 8 shows the resulting induced absorption in the low$\mathrm{OH}$-silica-core sample at times 0.5 and $16 \mathrm{~s}$ after that pulse as the black curves with peaks near $1.6 \mathrm{eV}$. These curves are compared with the (magnified to fit above $2.3 \mathrm{eV}$ ) spectra of

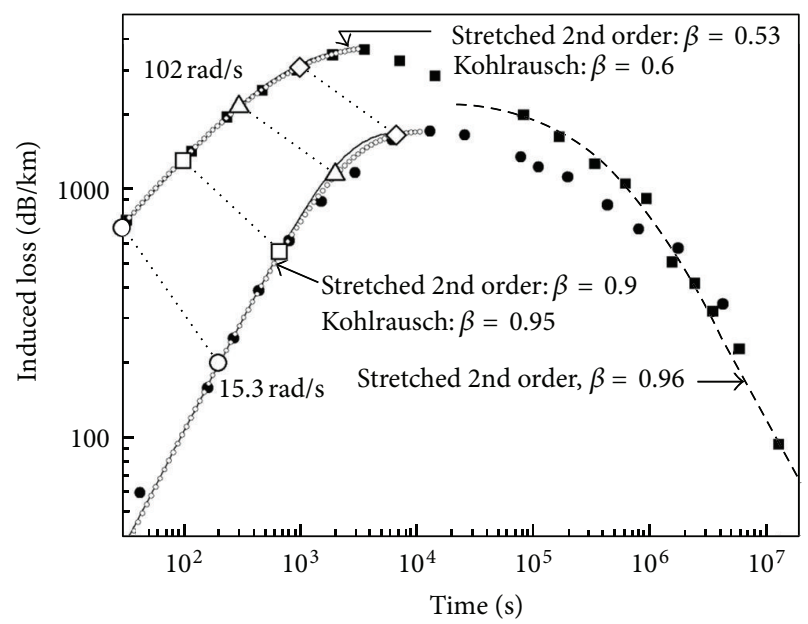

Figure 7: Growth and radiation-stimulated destruction of optical bands sampled at $900 \mathrm{~nm}$ for an identical virgin pair of low$\mathrm{OH} /$ low-Cl, aluminum-clad pure-silica-core (KS4V) optical fibers continuously subjected to two different $\gamma$-ray dose rates. Large hollow symbols link points on the two growth curves receiving equal accumulated doses. This is an adaptation of a figure in [48], where further information about the data collection and curve fitting can be found.

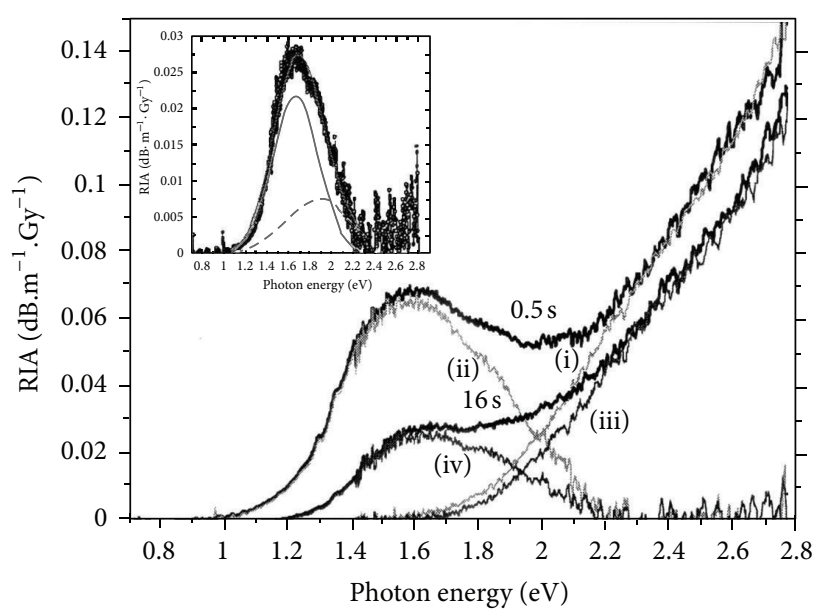

FIGURE 8: Pulsed-X-ray-induced spectra of a pair of optical fibers with pure silica cores, one with high-OH and the other with low$\mathrm{OH}$, decomposed to emphasize bands centered near $1.6 \mathrm{eV}$ unique to low-OH fiber [33]. Note rapid room-temperature decay of these metastable visible/near-IR bands.

the similarly irradiated and measured high-OH fibers (curves i and iii, resp.). Subtraction of curves $i$ and iii from the respective spectra of the low-OH fiber resulted in curves ii and iv, respectively, which have been decomposed in the inset into a pair of bands centered near 1.63 and $1.88 \mathrm{eV}$-virtually identical to the bands that I have assigned to STHs induced in low-OH-silica-core fibers continuously $\gamma$-irradiated at dose rates in the range of $\sim 0.15$ to $\sim 5 \mathrm{~Gy} / \mathrm{s}[44-46,48]$.

In order to better understand the results of Figure 8, it should be understood that $\gamma$-rays [49], X-rays [50], and $6.4 \mathrm{eV}$ laser photons [50] have each been shown to create free 
hydrogen atoms in $\mathrm{OH}$-containing silica glasses by radiolytic dissociation of hydroxl groups in according to:

$$
\equiv \mathrm{Si}-\mathrm{OH} \longrightarrow \equiv \mathrm{Si}-\mathrm{O} \bullet+\cdot \mathrm{H}^{0},
$$

where " $\equiv \mathrm{Si}-\mathrm{O} \bullet "$ is a nonbridging-oxygen hole center $(\mathrm{NBOHC})$ and the dots "•" indicate unpaired electrons, which in these particular cases have both been monitored by ESR. When such irradiations are carried out at $100 \mathrm{~K}$ or lower, the numbers of $\cdot \mathrm{H}^{0}$ s found in high-OH silicas before warming are typically $\sim 2$ to 3 times more numerous than any other paramagnetic defect $[25,49,50]$. Warming briefly to $\sim 150 \mathrm{~K}$ (or sometimes only to $\sim 130 \mathrm{~K}$ ) results in the disappearance of all $\bullet \mathrm{H}^{0} \mathrm{~s}$ due at least partially to the back reaction of (4). Those $\bullet \mathrm{H}^{0}$ s that neither back react nor immediately react with STHs or defect center precursors in the glass have been demonstrated to dimerize into ESR-silent $\mathrm{H}_{2}$ molecules, some of which subsequently diffuse in the temperature range $\sim 190-290 \mathrm{~K}$ to the sites of NBOHCs where they are "cracked" according to the reaction [25]:

$$
\equiv \mathrm{Si}-\mathrm{O} \bullet+\mathrm{H}_{2} \longrightarrow \equiv \mathrm{Si}-\mathrm{OH}+\bullet \mathrm{H}^{0} .
$$

The released hydrogen atom, $\bullet \mathrm{H}^{0}$ commonly reacts with precursors to form $E_{\beta}^{\prime}$ centers $[10,25,32]$ (or formyl radicals in the rare case of silica glasses containing traces of carbon monoxide [49]).

STHs have never been observed in high-OH glasses, presumably because the initially created $\bullet \mathrm{H}^{0} \mathrm{~s}$ immediately react with STHs to form ESR-silent protons (which in $a-\mathrm{SiO}_{2}$ gate oxides of MOS structures drift toward the $\mathrm{SiO}_{2} / \mathrm{Si}$ interface under positive gate bias to form deleterious $\mathrm{P}_{\mathrm{b}}$ centers [2]). Thus, the experiment of [33] becomes additional evidence that radiation-induced optical bands centered near 1.63 and $1.88 \mathrm{eV}$ in low-OH pure-silica-core optical fibers are truly attributable to STHs-even though these optical-fiber STHs differ from the bands at 2.16 and $2.60 \mathrm{eV}$ that unambiguously characterize $\mathrm{STH}_{2}$ and $\mathrm{STH}_{1}$, respectively, in irradiated bulk silica [47].

\section{Superiority of Fractal Kinetics for Assessing the Kinetics of Radiation-Induced Defects in Glasses}

In [48] I reported my derivations of first- and second-order fractal kinetic processes relevant to radiation-induced defect creation in glasses and their thermally induced decays at ambient temperature. These relations cannot be applied to situations where decays are radiation induced. Fortunately, however, Vladimir Mashkov has derived the fractal kinetic equations for the growth and radiolytic decay of defects in glasses [51]. Indeed, Vladimir's work preceded mine and inspired and guided me to do my own derivations for the case of thermally decaying defects [48].

So why are fractal kinetic formalisms superior to the "stretched exponential" Kohlrausch function, given that in both cases the solutions are functions of $(k t)^{\beta}$, where $k$ is an effective rate constant, $t$ is time, and $0<\beta<1$ ? Well, my answer is that the parameterizations of the fractal formalisms that I obtained by changing the dimensionless variable $k t \rightarrow$ $(k t)^{\beta}$ for both the classical first-order and classical secondorder kinetic equations (i) explicitly pertain to the thermal decay of the radiation-induced defects, (ii) result in solutions that have been found to fit the experimental data much better than by any other means, and (iii) have also revealed some striking, totally unexpected, and potentially valuable empirical rules [48], which the ad hoc parameterizations of the strictly first-order Kohlrausch function conceal. Indeed, Klafter and Shlesinger [52] have shown that three very different theoretical models leading to same Kohlraush law all have a common underlying mathematical structure, whereas in the present case the mathematical structures are particular to the specific models.

Figure 9 illustrates the most striking empirical rule that I discovered [48] by using my new fractal formalisms to fit the growth in optical attenuation at $1300 \mathrm{~nm}$ recorded for four spools each of two sets of Ge-doped-silica-core optical fibers-one of the sets being multimode (MM) and the other single-mode (SM) - during $\gamma$-irradiations at 0.0045 , 0.17 , and $3.4 \mathrm{~Gy} / \mathrm{s}$, and either an $8.8 \times 10^{-6} \mathrm{~Gy} / \mathrm{s}$ nuclearreactor irradiation or a $1 \times 10^{-4} \mathrm{~Gy} / \mathrm{s} \gamma$-irradiation. All of the spectral data that I fitted were acquired by Joe Friebele and his group at the Naval Research Laboratory and had been previously reported in [53]. The stunning features of Figure 9 are the facts that (i) the fractal rate coefficients $k$ in both first- and second-order are essentially coincident and (ii) they turn out to define a single linear function of dose rate over six orders of magnitude in dose rate! Needless to say, this outcome offers genuine hope that it should be possible to safely extrapolate these parameters into dose-rate regimes greater than $4 \mathrm{~Gy} / \mathrm{s}$ (for which sources are generally unavailable), as well as backwards into the realm of dose rates lower than $10^{-5} \mathrm{~Gy} / \mathrm{s}$ (in which case complete growth curves such as those of Figure 10 could not be obtained in practical laboratory times).

4.1. There Are Two Other Fractal Kinetic Parameters Besides $k$. Figure 9 is only a part of a much longer story [48], which I will attempt only to outline here. Most importantly, I must confess that there are two additional fractal measurables derivable from the fitting functions, which also depend on the experimental dose rate $\check{\mathrm{D}}$ :

(A) $\beta$ is the exponent of the dimensionless variable, $(k t)$, that appears in both the first- and secondorder fractal-kinetic differential equations and their solutions, wherein $k$ is the deduced fractal rate coefficient plotted on the ordinate of Figure 9 and $t$ is the running time of the irradiation in seconds. The maximum irradiation times, $t_{\max }$, were arranged in [53] to achieve as nearly as possible the same total doses, $\check{\mathrm{D}}_{i} \times t_{\max (i)}$, for each of the four experimental dose rates, $\check{\mathrm{D}}_{i}$, where $i=1,2,3$, or 4 . (However, this ideal objective was not quite achieved for the two lowest dose rates in Figure 10.) By means of fitting the experimental growth curves, I found $\beta$ to vary 


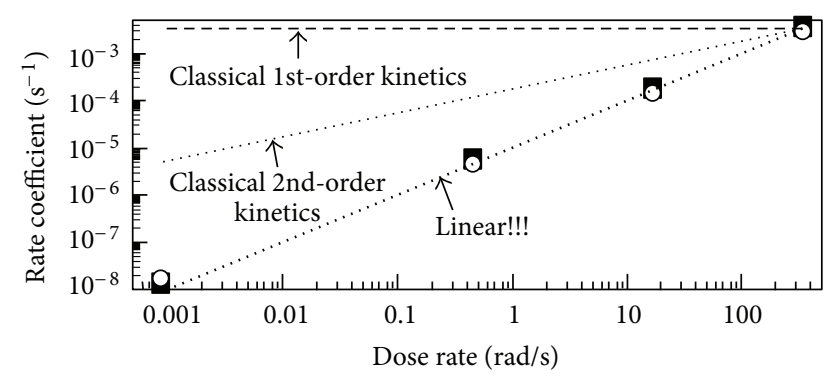

FIGURE 9: Fractal-kinetic rate coefficients $k$ determined as functions of dose rate D by fitting [48] growth curves comprising induced losses at $1300 \mathrm{~nm}$ as functions of accumulated dose from $\sim 7 \mathrm{~Gy}$ to $\sim 10^{4} \mathrm{~Gy}$ in four virgin samples (one curve for each dose rate) of the MM Ge-doped-silica-core fiber of [53]. The fractal first-order (open circles) and second-order (solid squares) fitting functions (described in detail in [48]) were employed here without taking into account a small population of dose-rate-independent (nondecaying) defects inferred to be copresent. When corrections were made to account for such nondecaying defect populations, the data points collapsed onto the slope-1 line almost perfectly. (Note that Figure 10 shows the similarly fitted curves for the corresponding SM fibers, each of which takes into account the non-decaying components.)

(concave downward) from $\sim 1.0$ at the lowest dose rates to $\sim 0.5$ at the highest dose rate [48].

(B) $N_{\text {sat }}$ is the saturation defect concentration at infinite time $(t \rightarrow \infty)$ which, though formulated differently in the two kinetic orders considered, was found to behave nearly identically when each was plotted versus the dose rates, $\check{\mathrm{D}}_{i}$. By means of my fits, I found $N_{\text {sat }}$ to increase by a factor of $\sim 100$ as $\check{D}$ increased by $\sim 6$ orders of magnitude [48], with an average slope $\sim \beta / 2$ (vis-à-vis the slope of 1.00 determined for $k$ in Figure 9).

4.2. Major Differences between Classical-Kinetic Constants and Fractal-Kinetic Coefficients. In my fractal derivations [48] both $k$ and $N_{\text {sat }}$ are expressed in terms of the dose rates, $\check{\mathrm{D}}$, in combination with the radiation-induced-creation and thermal-decay-rate coefficients, $K$ and $R$, respectively, which are constants in the classical rate equations upon which they are based.

In my 1st-order fractal-kinetic rate equation I found that $k=R$ (which was no longer a constant; see below) while in its solution I found that $N_{\text {sat }}=(K \overline{\mathrm{D}} / R)^{\beta}$.

In my 2nd-order fractal-kinetic rate equation $I$ found that $k=(K \check{D} R)^{1 / 2}$ and in its solution I found that $N_{\text {sat }}=$ $(K \overline{\mathrm{D}} / R)^{\beta / 2}$.

Given these strikingly different formulae for the two fractal-kinetic orders, it was surprising to find that the calculated values of $k$ (see Figure 9), as well as those of $\beta$ and $N_{\text {sat }}$ (cf. [48]) for each of these two fractal-kinetic orders coincided rather accurately for every sampled dose rate. Again, all values of $k, \beta$, and $N_{\text {sat }}$ were derived from independent fits of my first- and second-order fractal solutions for two sets (MM and SM) of four experimental growth curves corresponding

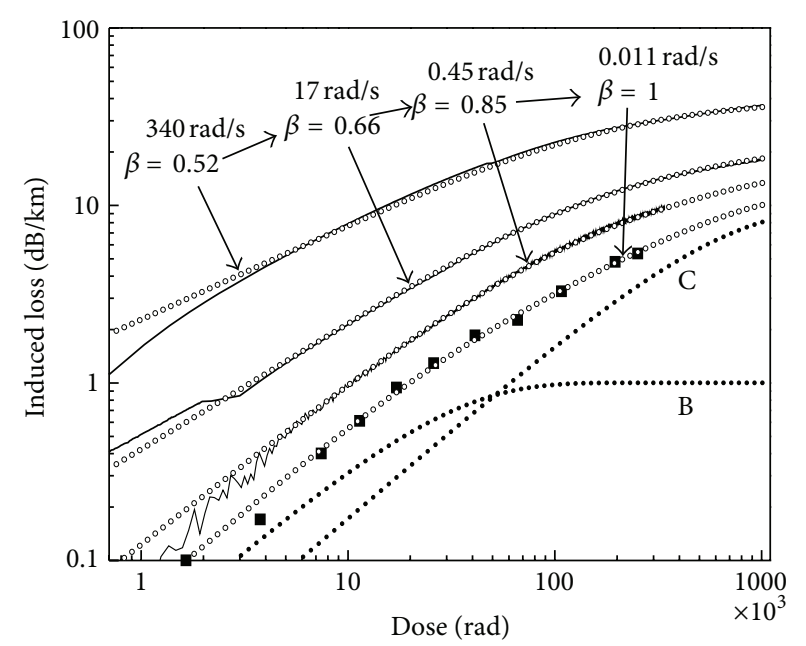

FIGURE 10: Growth of induced attenuation at $1300 \mathrm{~nm}$ in lengths of Corning single mode (SM) Ge-doped-silica-core optical fibers separately subjected to $\gamma$-ray irradiations at dose rates of $0.011,0.45$, 17 , and $340 \mathrm{rad} / \mathrm{s}$ at $50^{\circ} \mathrm{C}$ (continuous solid curves and black squares) [53]. The small open circles are best fits to these four data sets based primarily on the fractal second-order-kinetic growth solutions given as (equation (17) of [48]) for defects (termed "Population A") that thermally decay at ambient temperature. However, after the best-fit Population-A simulations were accomplished and found to be less than perfect, these fits were improved upon by cut-and-try additions of first one, and finally two nondecaying (dose-rate independent) populations, termed B and C. The finally optimized Population B and $\mathrm{C}$ growth curves are illustrated here by the correspondingly labeled dotted curves. Because these additional populations were independent of dose rate by design, the very same pair of curves had to be added to each of the four fractal-kinetic simulations comprising the dose-rate-dependent parts of the four growth curves in order to achieve the final fits, such as the ones depicted here. Figure from [48].

to four different dose rates $\check{D}$ (Figure 10 shows the secondorder fits of the SM data).

Another surprising outcome turned out to be the empirical rules [48]. In the 1st-order case, $R \propto \check{\mathrm{D}}$ and $K \propto \check{\mathrm{D}}^{1 / 2}$, whereas in the 2 nd-order case, $K / R$ is independent of $\check{D}$ while $K \times R \propto \check{\mathrm{D}}$.

4.3. What Are the Defects Responsible for the RadiationInduced Losses at $1300 \mathrm{~nm}$ ? After a long period of time thinking about it, I am finally convinced that the "Population A" attenuations must be manifestations of the long-wavelength tails of the optical bands of self-trapped holes, which peak near 1.63 and $1.88 \mathrm{eV}$ in low-OH silica-based optical fibers [44-46] (see Figure 11). If I am right about this, then it should be possible to radiation harden low-OH pure silicacore optical fibers, or fiber devices, against photo darkening at $1300 \mathrm{~nm}$ by pre-irradiation at a relatively low dose rate (cf. Section 3.3).

Populations B and C in the Ge-doped-silica fibers discussed above make much smaller (but permanent) contributions to the radiation-induced losses at $1300 \mathrm{~nm}$. Clearly, they 


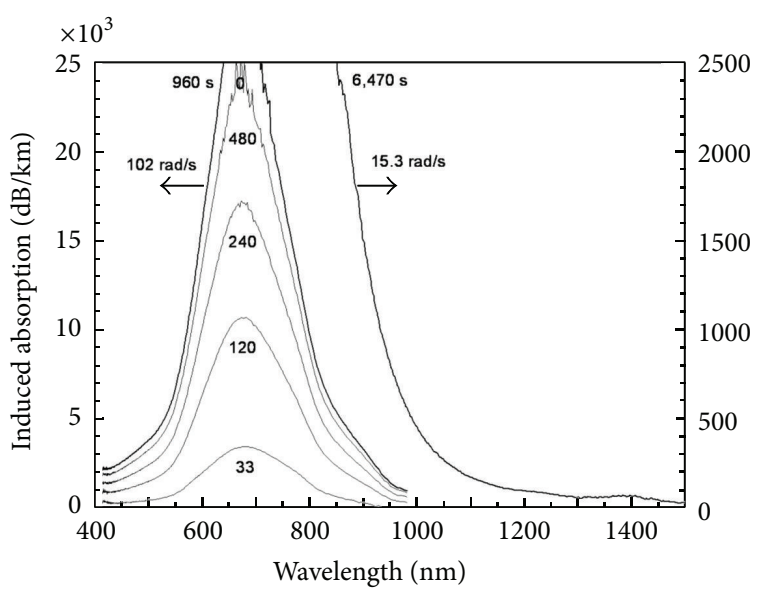

FIGURE 11: $\gamma$-ray-induced optical absorption bands attributable to metastable self-trapped holes in separate lengths of an aluminumclad, low-OH, F-doped-silica-core optical fiber at $27^{\circ} \mathrm{C}$ in the dark. The short-wavelength spectra were recorded in situ using a $1 \mathrm{~m}$ length of fiber and a prism-based CCD-camera spectrometer [48]; whereas long-wavelength spectrum was recorded in situ using a $10 \mathrm{~m}$ length and an optical signal analyzer. Dose rates in $\mathrm{rad} / \mathrm{s}$ and irradiation times in seconds are indicated in the figure. The dose delivered to the $10 \mathrm{~m}$ length was about the same as for the $960 \mathrm{~s}$ exposure of the $1 \mathrm{~m}$ length (note that the right-hand scale is expanded by a factor of 10). Figure from [48].

must comprise the long-wavelength tails of the nearest (non$\mathrm{STH})$ bands at shorter wavelengths. These would be the $\mathrm{Ge}(1)$ $[5,6]$ and $\mathrm{GeX}[54,55]$ trapped-electron centers centered at $4.4 \mathrm{eV}$ and $2.6 \mathrm{eV}$, respectively, and perhaps also the $2.0 \mathrm{eV}$ band (e.g., [56]) due to NBOHCs.

The nomenclature "GeX" was introduced by Anoikin and his coworkers [54] to express its unknown place in the Pantheon of Ge-doped-silica-glass defects. However, there was one clue. By rerecording the optical spectra of their $\gamma$-irradiated polymer-clad, Ge-doped-silica-core fibers one year later, they found that the number density of Ge(1) centers had diminished by about $70 \%$ while GeX had increased by an amount approximately equal to the number of $\mathrm{Ge}(1)$ centers lost. Accordingly, I speculate that $\mathrm{GeX}$ may be a $\mathrm{Ge}(1)$ that has reacted with atmospheric hydrogen that penetrated their polymer jackets. If my guess is right, then $\mathrm{Ge}(2)$ should have been completely destroyed in less than a year's time (cf. Section 2.2.1). However, Anoikin et al. [54] did not record their spectra to energies higher than $3.2 \mathrm{eV}$, so further research will be needed to find out what happens to the $5.8 \mathrm{eV}$ band (associated with $\mathrm{Ge}(2)$; see Figure 2) in irradiated polymer-clad fibers subsequently exposed to the atmosphere for extended periods of time.

4.4. Fractal-Kinetic Isothermal Decay Curves. Postirradiation decay curves were measured only for the MM and SM Gedoped fiber coils exposed to the highest dose of $1 \mathrm{Mrad}$ at a dose rate of $340 \mathrm{rad} / \mathrm{s}$ [53]. My study of these curves yielded some good news and some bad news.

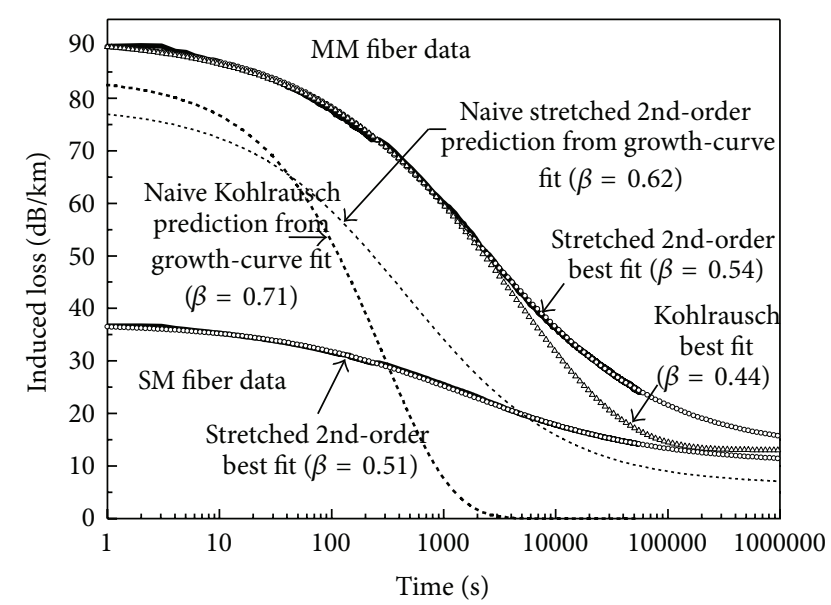

FIgURE 12: Thermal decay curves of MM and SM Ge-doped-silicacore optical fibers following a 1-Mrad irradiation at $340 \mathrm{rad} / \mathrm{s}$ (bold black curves) [53]. The SM data correspond to the upper curve of the growth data of Figure 10. Other features are explained in the text. Figure from [48]. Although virtually impossible to discern in the figure above, the experimental data terminate at $60,000 \mathrm{~s}$; thus, the open circles at longer times are solely extensions of the fits to the data at shorter times.

The good news is that the existence of nondecaying (doserate independent) defect centers was confirmed, and the unambiguous numbers of these nondecaying centers were found to agree rather well with the sum of the high-dose ends of the "Populations B and C" growth curves that I had iterated into my simulations of the growth curves of Figure 10. This verification came in the form of the time-independent induced losses $\sim 10 \mathrm{~dB} / \mathrm{km}$ that I was forced to add to my fractal-kinetic decay-equation simulations in order to match the actual decay curves shown as the bold black lines in Figure 12.

The "bad news" was that the fractal decay-rate constants $R$ that I used so successfully to simulate the dose-ratedependent growth curves of Figure 10 were too large by factors of $\sim 15$ to fit the actual decay curves of Figure 12 . The naïveté of my notion that they should match exactly is illustrated by the light dashed curves in Figure 12. My successful fits using substantially larger values of $R$ in my fractal-kinetic second-order decay solution (Equation (20) of [48]) are shown in Figure 12 as the small hollow circles. My fractal first-order-kinetic best-fit ("Kohlrausch best fit": small hollow triangles) is clearly inferior. In fact, this bow toward the second-order solution is good news for my fractal-kinetic formalisms, given that the recombination of electrons and holes is a second-order kinetic process.

Apropos of predicting the decay curve from the parameters of the growth curve, it has been proven possible to dissect power-law growth curves into a succession of classical $n$ th-order-kinetic solutions wherein the dominant subpopulations are characterized by growth and thermal decay rate constants $K(\mathrm{D})$ and $R(\mathrm{D})$, respectively, both of which decline in magnitude with increasing dose $\mathrm{D}$ according to rigorously derived rules [57]. Then for power laws $0<\beta<$ 1 , kinetic orders $n$, and experimental irradiation times $t_{\text {irrad }}$, 
the characteristic postirradiation decay time constants $\tau_{c}$ are predicted to be

$$
\begin{gathered}
\tau_{c}=\frac{t_{\mathrm{irrad}}}{[(n-1)(1-\beta)]} \quad \text { for } n>1, \\
\tau_{c}=\frac{t_{\mathrm{irrad}}}{[1-\beta]} \quad \text { for } n=1 .
\end{gathered}
$$

This prediction has actually worked out nicely in one experimental case [57]. However, the caveat here is that (6) have succeeded only when applied to pure power-law growth curves. Whether or not an analogous system can ever be worked out for continuously curved growth curves such as those in Figure 10 is uncertain.

\section{Conclusions}

It is clear that a half century of electron-spin-resonance and optical studies of radiation-induced point defects in pure and doped silica glasses has been an immense boon for understanding the performances of both bulk and fiber-optic forms of these materials in radiation environments ranging from the Large Hadron Collider and the International Thermonuclear Experimental Reactor to outer space. Fortunately these studies are continuing, given the virtual infinity of trace impurities, manufacturing methods, environmental conditions, and end-user requirements to which these essential materials and devices will continue to be subjected. Hopefully, the body of knowledge incorporated into this paper and the references provided will stimulate future studies in areas that still remain unsettled while averting "reinvention of the wheel" in areas that are solidly established.

In particular, I hope that the reader will recognize from Section 4 that fractal kinetics is much more than just a systematized study of dose-rate-dependent attenuations induced in silica-based fiber optics by ionizing radiations. Rather, it is a rigorous mathematical formalism that perfectly matches the model pertaining to the experimental data and serendipitously provides a reliable means for extrapolating the results of dose-rate-dependence studies backward into time regimes so extended that the experiments cannot be completed in practical laboratory times and forward into suprahigh-dose-rate regimes for which no laboratory sources are likely to become available in the near future.

\section{Acknowledgments}

The author thanks Katsumi Tanimura for kindly providing his original data and curve fits, which he has replotted in Figure 4, and Ed Taylor for inviting him to speak on this theme at the SPIE 2011 Optics + Photonics Conference 8164, thereby inspiring an early version of this paper. He composed this paper without outside funding.

\section{References}

[1] D. L. Griscom, "Nature of defects and defect generation in optical glasses," Proceedings of SPIE, vol. 541, pp. 38-59, 1985.
[2] D. L. Griscom, "Hydrogen model for radiation-induced interface states in $\mathrm{SiO}_{2}$-on-Si Structures: a review of the evidence," Journal of Electronic Materials, vol. 21, no. 7, pp. 763-767, 1992.

[3] D. L. Griscom, "Amorphous materials: electron spin resonance," in Encyclopedia of Materials: Science and Technology, pp. 179186, Elsevier Science, 2001.

[4] D. L. Griscom, "Electron spin resonance," in Glass Science and Technology, vol. 4B of Advances in Structural Analysis, pp. 151251, Academic Press, New York, NY, USA, 1990.

[5] E. J. Friebele and D. L. Griscom, "Color centers in glass optical fiber waveguides," in Defects in Glasses, vol. 61 of MRS Proceedings, pp. 319-331, 1986.

[6] D. L. Griscom, "On the natures of radiation-induced point defects in $\mathrm{GeO}_{2}-\mathrm{SiO}_{2}$ glasses: reevaluation of a 26 -year-old ESR and optical data set," Optical Materials Express, vol. 1, pp. 400412, 2011.

[7] D. L. Griscom, "Trapped-electron centers in pure and doped glassy silica: a review and synthesis," Journal of Non-Crystalline Solids, vol. 357, no. 8-9, pp. 1945-1962, 2011.

[8] D. L. Griscom and E. J. Friebele, "Fundamental radiationinduced defect centers in synthetic fused silicas: atomic chlorine, delocalized e centers, and a triplet state," Physical Review $B$, vol. 34, no. 11, pp. 7524-7533, 1986.

[9] R. A. Weeks, "Paramagnetic resonance of lattice defects in irradiated quartz," Journal of Applied Physics, vol. 27, no. 11, pp. 1376-1381, 1956.

[10] D. L. Griscom, "Characterization of three $E^{\prime}$-center variants in $\mathrm{X}$ - and $\gamma$-irradiated high purity a-SiO${ }_{2}$," Nuclear Instruments and Methods in Physics Research B, vol. 1, no. 2-3, pp. 481-488, 1984.

[11] D. L. Griscom and M. Cook, "29 Si superhyperfine interactions of the $\mathrm{E}^{\prime}$ center: a potential probe of range-II order in silica glass," Journal of Non-Crystalline Solids, vol. 182, no. 1-2, pp. 119-134, 1995.

[12] D. L. Griscom, "The natures of point defects in amorphous silicon dioxide," in Defects in $\mathrm{SiO}_{2}$ and Related Dielectrics: Science and Technology, G. Pacchioni, L. Skuja, and D. L. Griscom, Eds., pp. 117-159, Kluwer Academic Publishers, Dordrecht, The Netherlands, 2000.

[13] G. Buscarino, S. Agnello, and F. M. Gelardi, " $\mathrm{Si}^{29}$ hyperfine structure of the $\mathrm{E}_{\alpha}^{\prime}$ center in amorphous silicon dioxide," Physical Review Letters, vol. 97, no. 13, Article ID 135502, 2006.

[14] M. Jivanescu and A. Stesmans, "Multi-frequency ESR analysis of $\mathrm{E}_{\delta}^{\prime}$ defect in $\mathrm{a}_{-} \mathrm{SiO}_{2}$," in Proceedings of the 8th Symposium $\mathrm{SiO} 2$, Advanced Dielectrics and Related Devices, Varenna, Italy, 2010.

[15] D. L. Griscom, "Electron spin resonance characterization of self-trapped holes in amorphous silicon dioxide," Journal of Non-Crystalline Solids, vol. 149, no. 1-2, pp. 137-160, 1992.

[16] D. L. Griscom, "Self-trapped holes in pure-silica glass: a history of their discovery and characterization and an example of their critical significance to industry," Journal of Non-Crystalline Solids, vol. 352, no. 23-25, pp. 2601-2617, 2006.

[17] J. A. Weil, "A demi-century of magnetic defects in $\alpha$ quartz," in Defects in $\mathrm{SiO}_{2}$ and Related Dielectrics: Science and Technology, pp. 197-212, Kluwer Academic, London, UK, 2000.

[18] E. J. Friebele, D. L. Griscom, and G. H. Sigel, "Defect centers in a germanium-doped silica-core optical fiber," Journal of Applied Physics, vol. 45, no. 8, pp. 3424-3428, 1974.

[19] J. Isoya, J. A. Weil, and R. F. C. Claridge, "The dynamic interchange and relationship between germanium centers in $\alpha$ quartz," The Journal of Chemical Physics, vol. 69, no. 11, pp. 4876$4884,1978$. 
[20] R. J. McEachern and J. A. Weil, " ${ }^{17} \mathrm{O}$ hyperfine interaction for the $\left[\mathrm{GeO}_{4}\right]_{\mathrm{I}, \mathrm{II}}{ }^{-}$and $\left[\mathrm{GeO}_{4} / \mathrm{Li}\right]_{\mathrm{A}, \mathrm{C}}{ }^{0}$ centers in an enriched crystal of $\alpha$-quartz," Physical Review B, vol. 49, no. 10, pp. 66986709, 1994.

[21] A. Alessi, S. Girard, M. Cannas, S. Agnello, A. Boukenter, and Y. Ouerdane, "Evolution of photo-induced defects in Ge-doped fiber/preform: influence of the drawing," Optics Express, vol. 19, no. 12, pp. 11680-11690, 2011.

[22] K. Nagasawa, T. Fujii, Y. Ohki, and Y. Hama, "Relation between $\mathrm{Ge}(2)$ center and $11.9 \mathrm{mT}$ hyperfine structure of ESR spectra in Ge-doped silica fibers," Japanese Journal of Applied Physics, vol. 27, no. 2, pp. 240-243, 1988.

[23] A. A. Bobyshev and V. A. Radtsig, "EPR study of the centers of chemisorption of certain gases on $\mathrm{GeO}_{2}$ surface," Kinetics and Catalysis, vol. 22, pp. 1229-1235, 1982.

[24] T. E. Tsai and D. L. Griscom, "On the structures of hydrogenassociated defect centers in irradiated high-purity a- $\mathrm{SiO}_{2}: \mathrm{OH}$," Journal of Non-Crystalline Solids, vol. 91, no. 2, pp. 170-179, 1987.

[25] D. L. Griscom, "Thermal bleaching of x-ray-induced defect centers in high purity fused silica by diffusion of radiolytic molecular hydrogen," Journal of Non-Crystalline Solids, vol. 68, no. 2-3, pp. 301-325, 1984.

[26] D. L. Griscom, G. H. Sigel, and R. J. Ginther, "Defect centers in a pure-silica-core borosilicate-clad optical fiber: ESR studies," Journal of Applied Physics, vol. 47, no. 3, pp. 960-967, 1976.

[27] M. G. Jani, R. B. Bossoli, and L. E. Halliburton, "Further characterization of the $\mathrm{E}_{1}^{\prime}$ center in crystalline $\mathrm{SiO}_{2}$," Physical Review B, vol. 27, no. 4, pp. 2285-2293, 1983.

[28] R. Schnadt and A. Räuber, "Motional effects in the trapped-hole center in smoky quartz," Solid State Communications, vol. 9, no. 2, pp. 159-161, 1971.

[29] K. L. Brower, "Electron paramagnetic resonance of $\mathrm{Al} \mathrm{E}_{1}^{\prime}$ centers in vitreous silica," Physical Review B, vol. 20, no. 5, pp. 1799-1811, 1979.

[30] A. N. Trukhin, A. Sharakovski, J. Grube, and D. L. Griscom, "Sub-band-gap-excited luminescence of localized states in $\mathrm{SiO}_{2}$-Si and $\mathrm{SiO}_{2}-\mathrm{Al}$ glasses," Journal of Non-Crystalline Solids, vol. 356, no. 20-22, pp. 982-986, 2010.

[31] D. L. Griscom, " $\gamma$ and fission-reactor radiation effects on the visible-range transparency of aluminum-jacketed, all-silica optical fibers," Journal of Applied Physics, vol. 80, no. 4, pp. 2142$2155,1996$.

[32] D. L. Griscom, D. B. Brown, and N. S. Saks, "Nature of radiationinduced point defects in amorphous $\mathrm{SiO}_{2}$ and their role in $\mathrm{SiO}_{2}$ on-Si structures," in The Physics and Chemistry of $\mathrm{SiO}_{2}$ and the $\mathrm{Si}-\mathrm{SiO}_{2}$ Interface, pp. 287-297, Plenum, New York, NY, USA, 1988.

[33] S. Girard, D. L. Griscom, J. Baggio, B. Brichard, and F. Berghmans, "Transient optical absorption in pulsed-X-ray-irradiated pure-silica-core optical fibers: influence of self-trapped holes," Journal of Non-Crystalline Solids, vol. 352, no. 23-25, pp. 26372642, 2006.

[34] J. H. Konnert, P. D’Antonio, and J. Karle, "Comparison of radial distribution function for silica glass with those for various bonding topologies: use of correlation function," Journal of NonCrystalline Solids, vol. 53, no. 1-2, pp. 135-141, 1982.

[35] G. Pacchioni and A. Basile, "Calculated spectral properties of self-trapped holes in pure and $\mathrm{Ge}$-doped $\mathrm{SiO}_{2}$," Physical Review B, vol. 60, no. 14, pp. 9990-9998, 1999.

[36] A. V. Kimmel, P. V. Sushko, and A. L. Shluger, "Structure and spectroscopic properties of trapped holes in silica," Journal of Non-Crystalline Solids, vol. 353, no. 5-7, pp. 599-604, 2007.
[37] A. C. Wright, "Defect-free vitreous networks: the idealized structure of $\mathrm{SiO}_{2}$ and related glasses," in Defects in $\mathrm{SiO}_{2}$ and Related Dielectrics: Science and Technology, pp. 1-35, Kluwer Academic Publishers, London, UK, 2000.

[38] A. C. Wright, "Neutron and x-ray amorphography," in Experimental Techniques of Glass Science, pp. 205-314, The American Ceramic Society, Westerville, Ohio, USA, 1993.

[39] D. L. Griscom, "Self-trapped holes in amorphous silicon dioxide," Physical Review B, vol. 40, no. 6, pp. 4224-4227, 1989.

[40] P. V. Chernov, E. M. Dianov, and V. N. Karpechev, "Spectroscopic manifestations of self-trapped holes in silica," Physica Status Solidi B, vol. 155, pp. 633-640, 1989.

[41] E. Harari, S. Wang, and B. S. H. Royce, "Low-temperature irradiation effects in $\mathrm{SiO}_{2}$-insulated MIS devices," Journal of Applied Physics, vol. 46, no. 3, pp. 1310-1317, 1975.

[42] K. Nagasawa, M. Tanabe, K. Yahagi, A. Iino, and T. Kuroha, "Gamma-ray induced absorption band at $760 \mathrm{~nm}$ in pure silica core optical fibers," Japanese Journal of Applied Physics, vol. 23, no. 5, pp. 606-611, 1984.

[43] K. Nagasawa, M. Tanabe, and K. Yahagi, "Gamma-ray-induced absorption bands in pure-silica-core fibers," Japanese Journal of Applied Physics, vol. 23, no. 12, pp. 1608-1613, 1984.

[44] D. L. Griscom, "Visible/infra-red absorption study in fiber geometry of metastable defect states in high-purity fused silicas," Materials Science Forum, vol. 239-241, pp. 19-24, 1997.

[45] D. L. Griscom, "Radiation hardening of pure-silica-core optical fibers: reduction of induced absorption bands associated with self-trapped holes," Applied Physics Letters, vol. 71, no. 2, pp. 175177, 1997.

[46] D. L. Griscom, “ $\gamma$-Ray-induced visible/infrared optical absorption bands in pure and F-doped silica-core fibers: are they due to self-trapped holes?" Journal of Non-Crystalline Solids, vol. 349, no. 1-3, pp. 139-147, 2004.

[47] Y. Sasajima and K. Tanimura, "Optical transitions of selftrapped holes in amorphous $\mathrm{SiO}_{2}$," Physical Review B, vol. 68, no. 1, Article ID 014204, pp. 142041-142047, 2003.

[48] D. L. Griscom, "Fractal kinetics of radiation-induced pointdefect formationand decay in amorphous insulators: application to color centers insilica-based optical fibers," Physical Review B, vol. 64, no. 17, Article ID 174201, 2001.

[49] D. L. Griscom, M. Stapelbroek, and E. J. Friebele, "ESR studies of damage processes in X-irradiated high purity a- $\mathrm{SiO}_{2}: \mathrm{OH}$ and characterization of the formyl radical defect," The Journal of Chemical Physics, vol. 78, no. 4, pp. 1638-1651, 1983.

[50] D. L. Griscom, "Growth and decay kinetics of defect centers in high-purity fused silicas irradiated at $77 \mathrm{~K}$ with X-Rays or 6.4-eV laser light," Nuclear Instruments and Methods in Physics Research B, vol. 46, no. 1-4, pp. 12-17, 1990.

[51] V. A. Mashkov, W. R. Austin, L. Zhang, and R. G. Leisure, "Fundamental role of creation and activation in radiationinduced defect production in high-purity amorphous $\mathrm{SiO}_{2}$," Physical Review Letters, vol. 76, no. 16, pp. 2926-2929, 1996.

[52] J. Klafter and M. F. Shlesinger, "On the relationship among three theories of relaxation in disordered systems," Proceedings of the National Academy of Sciences of the United States of America, vol. 83, pp. 848-851, 1986.

[53] E. J. Friebele, G. M. Williams, and W. D. Mack, "Qualified parts list optical fibers in radiation environments," in Optical Fiber Reliability and Testing, vol. 3848 of Proceedings of SPIE, pp. 232239, September 1999. 
[54] E. V. Anoikin, V. M. Mashinsky, V. B. Neustruev, and Y. S. Sidorin, "Effects of exposure to photons of various energies on transmission of germanosilicate optical fiber in the visible to near IR spectral range," Journal of Non-Crystalline Solids, vol. 179, pp. 243-253, 1994.

[55] D. L. Griscom, “ $\gamma$-ray-induced optical attenuation in Ge-dopedsilica fiber image guides," Journal of Applied Physics, vol. 78, no. 11, pp. 6696-6704, 1995.

[56] L. Skuja, "Section 1. Defect studies in vitreous silica and related materials: optically active oxygen-deficiency-related centers in amorphous silicon dioxide," Journal of Non-Crystalline Solids, vol. 239, no. 1-3, pp. 16-48, 1998.

[57] D. L. Griscom, M. E. Gingerich, and E. J. Friebele, "Model for the dose, dose-rate and temperature dependence of radiationinduced loss in optical fibers," IEEE Transactions on Nuclear Science, vol. 41, no. 3, pp. 523-527, 1994. 

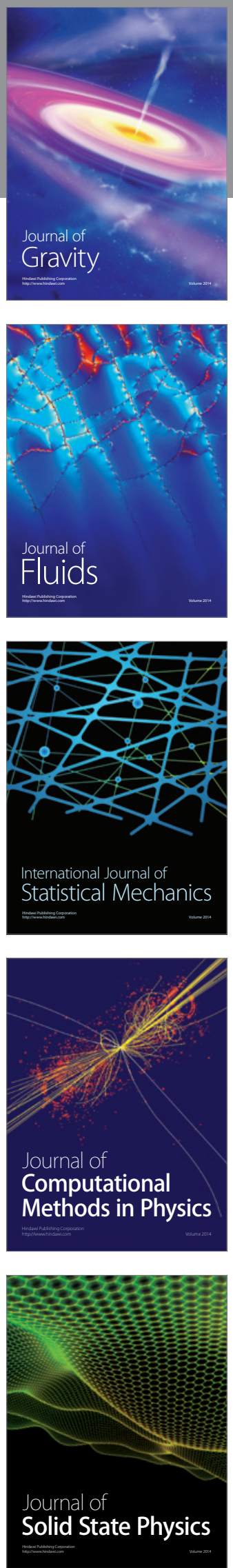

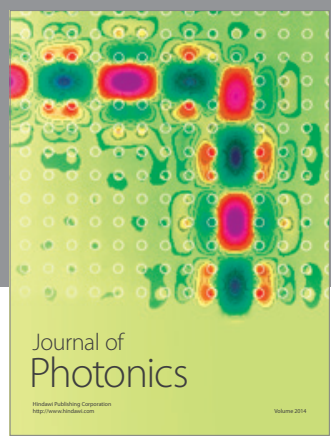

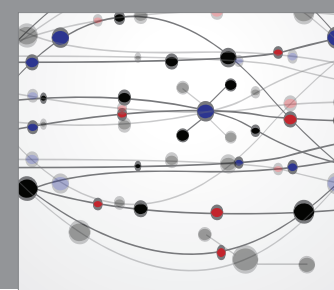

The Scientific World Journal

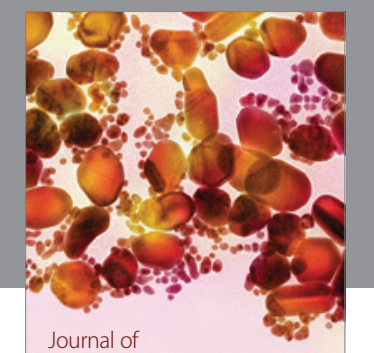

Soft Matter
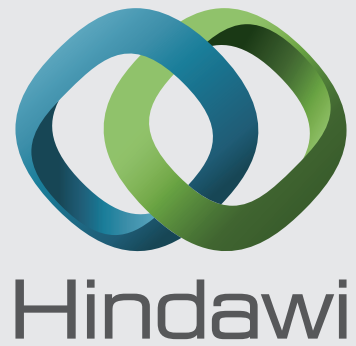

Submit your manuscripts at

http://www.hindawi.com
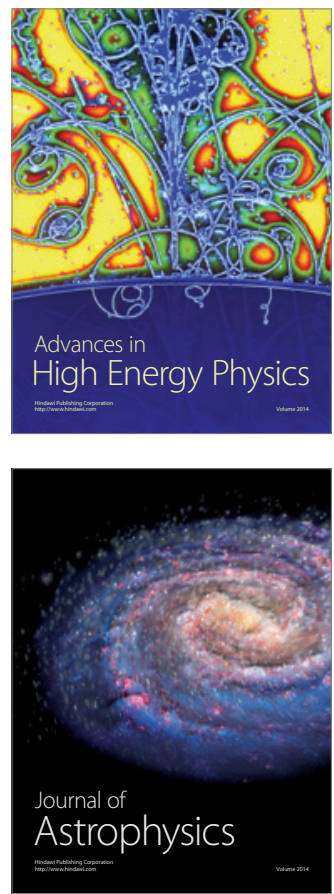
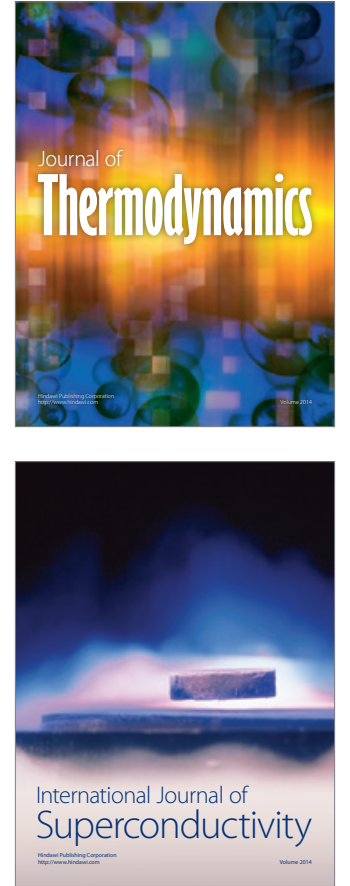
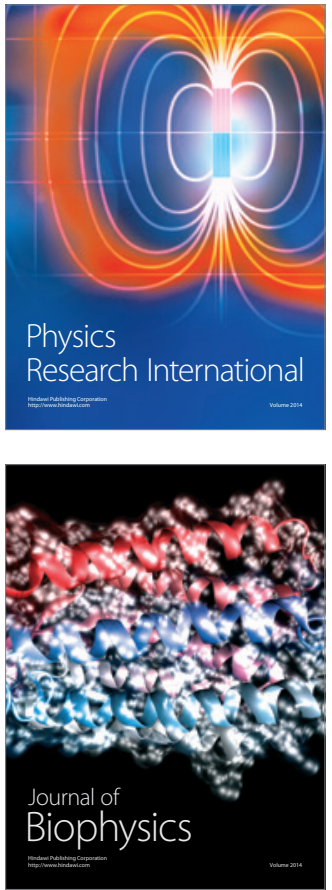
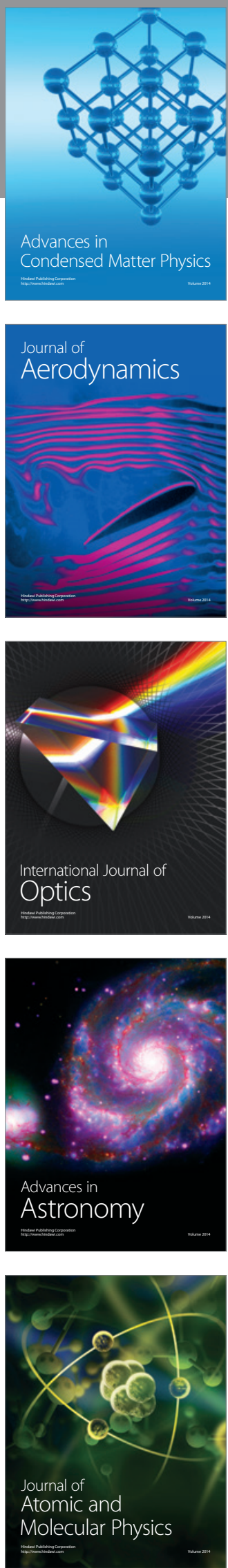